\title{
TEORIA DO PORTFÓLIO: UM ESTUDO SOBRE OS FATORES QUE INFLUENCIAM A ESCOLHA DO PERFIL DE INVESTIMENTO DA FASERN
}

\author{
T. S. A. DAMASCENO ${ }^{1 *}$, A. L. R. $\mathrm{MOL}^{2}$ e L. F. L. G. $\operatorname{COSTA}^{3}$ \\ ${ }^{1}$ Fundação Getúlio Vargas - FGV \\ ${ }^{2}$ Universidade Federal do Rio Grande do Norte - UFRN \\ ${ }^{3}$ Instituto Federal de Educação, Ciência e Tecnologia do Rio Grande do Norte - IFRN \\ thiago.damasceno@hotmail.com*
}

Artigo submetido em julho/2014 e aceito em novembro/2015

DOI: 10.15628/holos.2015.2259

\section{RESUMO}

Este trabalho tem como objetivo principal avaliar os fatores que influenciam a escolha do perfil de investimento dos participantes ativos da FASERN. Este estudo apresenta os fundamentos de risco e retorno, as preferências em relação ao risco, os perfis de risco e alguns dos seus desdobramentos. Esses conceitos devem ser conhecidos previamente para que deem suporte às decisões adequadas no momento de se fazer um investimento. A pesquisa pode ser considerada como descritivo-exploratória. Ela se propõe a descrever o comportamento da amostra quanto ao desempenho das variáveis, para tanto foi realizado um survey, por meio do uso de medidas de posição, como média, distribuições de frequência e gráficos e pelas análises de cluster e discriminante. Ao final da modelagem é possível identificar que apenas 4 variáveis foram significantes para discriminar os grupos ou explicá-los, são elas: área de atuação na empresa; formação acadêmica; grau de escolaridade e faixa etária que os avaliam em relação ao grau de conhecimento do mercado financeiro e a variável dependente "perfil de investimento". Também, define a que grupo pertence cada participante de acordo com o seu perfil de risco (conservador, moderado e agressivo).

PALAVRAS-CHAVE: Entidade Fechada de Previdência Complementar, Perfis de Risco, Metas de Investimentos, Análise de Cluster, Análise de Discriminante.

\section{PORTFOLIO THEORY: A STUDY ON THE FACTORS THAT INFLUENCING THE CHOICE OF INVESTMENT PROFILE OF FASERN}

\begin{abstract}
This paper aims to evaluate the factors that influence the choice of the investment profile of the FASERN's participants. This study presents the fundamentals of risk and return, risk profiles and some of its consequences. The research may be regarded as descriptive and exploratory. It aims to describe the behavior of the sample as the variables performance, for this was made a survey, by using of position measurements, such as mean, frequency distributions and graphs and by cluster
\end{abstract}

and discriminant analyzes. After the modeling, it is possible identify that only 4 variables were significant for discriminating groups or explain them, such as: field of work in the company; academic education, educational level and age range that evaluate them regarding to the knowledge level on financial market and the dependent variable "investment profile". Also, it defines which group belongs to each participant according to its risk profile (conservative, moderate and aggressive).

KEYWORDS: Closed Private Pension Entity, Risk Profiles, Investment Targets, Cluster Analysis, Discriminant Analysis. 


\section{INTRODUÇÃO}

A busca incessante do indivíduo pela segurança, em diferentes níveis, é uma preocupação constante. Devido aos grandes riscos e incertezas que afetam os trabalhadores do setor privado, grupos de pessoas e empresas decidiram unir esforços com o objetivo de proporcionar benefícios e renda complementar à previdência social.

Assim, o regime de previdência privada, o qual possui caráter essencialmente complementar, foi regulamentado, no Brasil, em 1979, cuja finalidade é prover os seus beneficiários que desejam receber valores superiores aos tetos dos benefícios dos regimes a que pertencem e para aqueles que trabalham no mercado informal, mas querem adquirir um plano de aposentadoria.

A Previdência Complementar Fechada integra o sistema de seguridade social e constitui um instrumento de grande eficiência para proteger o trabalhador brasileiro. No Brasil, segue o modelo consagrado pela maioria dos países desenvolvidos que compreende um conjunto integrado de ações dos poderes públicos e da sociedade, destinadas a assegurar os direitos dos cidadãos relativos à saúde, à previdência e à assistência.

De acordo com a ABRAPP (Associação Brasileira das Entidades Fechadas de Previdência Complementar), existem 324 Entidades Fechadas de Previdência Complementar (EFPC) no Brasil. Juntas, elas somam cerca de $\mathrm{R} \$ 630$ bilhões em investimentos, $\mathrm{R} \$ 657$ bilhões em ativos (disponível + realizável + permanente) que corresponde a 14,7\% do PIB de junho de 2013. Em seus quadros, há aproximadamente 2,3 milhões de participantes ativos, 3,7 milhões de dependentes e 697 mil assistidos (junho 2013). Esse sistema tem se mostrado uma ferramenta adequada para manter as contas públicas ajustadas, uma vez que sua lógica se baseia na constituição de poupança de longo prazo, a um custo baixo de captação e padrões razoáveis de remuneração. Os regimes de previdência básico e complementar são estruturas que compõem um mesmo sistema, devendo atuar de forma harmônica e integrada, apesar de serem independentes entre si.

Observa-se que os mercados globais têm exigido dos investidores a utilização de estratégias que maximizem a rentabilidade das suas carteiras de investimentos, minimizando o risco do portfólio. De acordo com Assaf Neto (2003), a teoria do portfólio trata, em suma, da composição de uma carteira excelente de ativos com o objetivo de maximizar o grau de satisfação do investidor pela relação risco/retorno. Dependendo do tipo de fundo, as carteiras geralmente podem ser mais ou menos diversificadas, podendo conter ativos de diversos tipos, tais como: ações, títulos de renda fixa, títulos cambiais, derivativos ou commodities negociadas em bolsas de mercadorias e futuros, entre outros. Todavia, para escolher a carteira mais apropriada é importante analisar a situação econômico-financeira, a tolerância ao risco, o período em que se pretende investir e, principalmente, o perfil de cada investidor.

Por conseguinte, a escolha do participante da FASERN (Fundação Cosern Previdência Complementar), por um dos perfis de investimento, deve estar adequada ao seu perfil e às suas metas de investimento.

Ao aplicar recursos financeiros em uma entidade fechada de previdência complementar, visando garantir uma aposentadoria melhor, o participante busca obter os melhores retornos provenientes de suas aplicações financeiras. Os meios que a Entidade dispõe para cumprir seu 
principal objetivo são representados por contribuições de suas patrocinadoras, de participantes e dos rendimentos resultantes das aplicações desses recursos em investimentos, que devem obedecer ao disposto na Resolução 3.846, de 25 de março de 2010 e alterações posteriores estabelecidas pelo Conselho Monetário Nacional (CMN).

Conforme art. 10으, do capítulo III, do Regulamento do Plano CD (Contribuição Definida) da FASERN, a inscrição como participante do Plano está aberta a todos aqueles que mantenham vínculo empregatício ou funcional com os patrocinadores. Atendendo aos critérios estabelecidos no Regulamento, o participante requer sua participação por meio do preenchimento de um formulário. Em seguida, o participante deverá escolher, dentre os cinco perfis existentes na entidade, aquele que estiver mais adequado ao seu perfil de investidor e só poderá mudar de perfil a cada doze meses. A composição desses, tem como parâmetros os limites da Política de Investimentos da entidade e da Secretaria de Previdência Complementar (SPC) expostos (Tabela 1), além do patrimônio acumulado de cada carteira.

Tabela 1: Patrimônio e os Limites das Carteiras de Investimentos

\begin{tabular}{|c|c|c|c|c|}
\hline \multirow{2}{*}{ CARTEIRA } & \multicolumn{2}{|c|}{ PATRIMÔNIO } & \multirow{2}{*}{$\begin{array}{c}\text { LIMITE \% } \\
\text { CMN } \\
\end{array}$} & \multirow{2}{*}{$\begin{array}{l}\text { LIMITE POLITICA } \\
\text { INVESTIMENTOS }\end{array}$} \\
\hline & $\mathbf{R} \$$ & $\%$ & & \\
\hline 1) RENDA FIXA & 84.036 .045 & 72,68 & $100 \%$ & $27,00 \% / 100,00 \%$ \\
\hline TÍTULO PÚBLICO & 56.816 .136 & 49,14 & $100 \%$ & $100 \%$ \\
\hline TITULO PRIVADO & 27.219 .908 & 23,54 & $80 \%$ & $80 \%$ \\
\hline 2) RENDA VARIÁVEL & 26.585 .612 & 22,99 & $70 \%$ & $0,00 \% / 50,00 \%$ \\
\hline 3) IMÓVEIS & & 0,00 & $8 \%$ & $0 \% / 8 \%$ \\
\hline 3) OP. PARTICIPANTES & 5.009 .571 & 4,33 & $15 \%$ & $0 \% / 15 \%$ \\
\hline TO T A L & 115.631 .227 & 100,00 & & \\
\hline
\end{tabular}

Fonte: FASERN (Março/2013)

Assim, busca-se através desta investigação observar a convergência teórica dos pressupostos supracitados. Para tanto, o artigo em questão está dividido em cinco partes: a presente introdução; referencial teórico que visa explorar os conceitos de risco e retorno, comportamento dos investidores, metas e decisões de investimento; a metodologia que demonstra o processo pelo qual os dados foram tratados através de uma análise descritiva, de cluster e discriminante; apresentação e análise de resultados, nessa seção são apresentadas informações referentes ao campo empírico observando as correlações existentes através do tratamento dos dados e conclusão apresentando as principais contribuições teóricas do estudo.

\section{REFERENCIAL TEÓRICO}

O risco e o retorno são dois conceitos fundamentais que devem ser considerados pelos gestores e investidores financeiros a fim de maximizar os investimentos. Segundo Brigham, Gapenski e Ehrhardt (2001), risco é a probabilidade de algum evento desfavorável acontecer. Já o conceito de retorno, para esses autores, é medido pelo desempenho financeiro de um investimento.

Sob a perspectiva financeira, risco é a consequência de uma decisão de investimento, sobre a qual há uma expectativa de ganho, sabendo-se que existe a possibilidade de perda. Já retorno é o total de ganhos ou prejuízos dos proprietários, decorrentes de um investimento, durante um determinado período de tempo. Segundo Ross, Westerfield e Jaffe (2002), a parcela inesperada do retorno é o verdadeiro risco de qualquer investimento. 
Ainda sobre risco, Assaf Neto (2003) menciona que ele pode ser mensurado pela variabilidade dos retornos projetados em torno do retorno esperado, isto é, pelo grau de dispersão dos retornos em relação à média. O desvio-padrão é, portanto, a medida estatística usualmente adotada para quantificar o risco de um ativo.

Segundo Markowitz, o modelo da teoria do portfólio assume que os investidores são avessos ao risco, o que significa que dados dois ativos que oferecem o mesmo retorno esperado, os investidores preferem o de menor risco. Assim, um investidor aumentará o risco apenas se é compensado pelo aumento do rendimento esperado. Inversamente, um investidor que deseja obter rentabilidades superiores deve aceitar mais risco.

Existem três tipos de retorno: o esperado que corresponde a remuneração que os investidores requerem para manter suas aplicações no ativo considerado; o exigido: aquele que em um mercado eficiente, corresponde ao retorno esperado e o real: que é o efetivo do investimento ou da aplicação (BRIGHAM, GAPENSKI E EHRHARDT, 2001).

Gitman (2001) afirma que existem três comportamentos básicos dos investidores (e gestores) em relação ao risco (Figura 1):

- Indiferença ao risco - quando o risco vai de um ponto $\mathrm{x}_{1}$ para $\mathrm{x}_{2}$ a taxa de retorno exigida não muda.

- Aversão ao risco - a taxa de retorno exigida aumenta em razão de um incremento no risco.

- Tendentes ao risco - a taxa de retorno exigida diminui em razão de um aumento no risco.

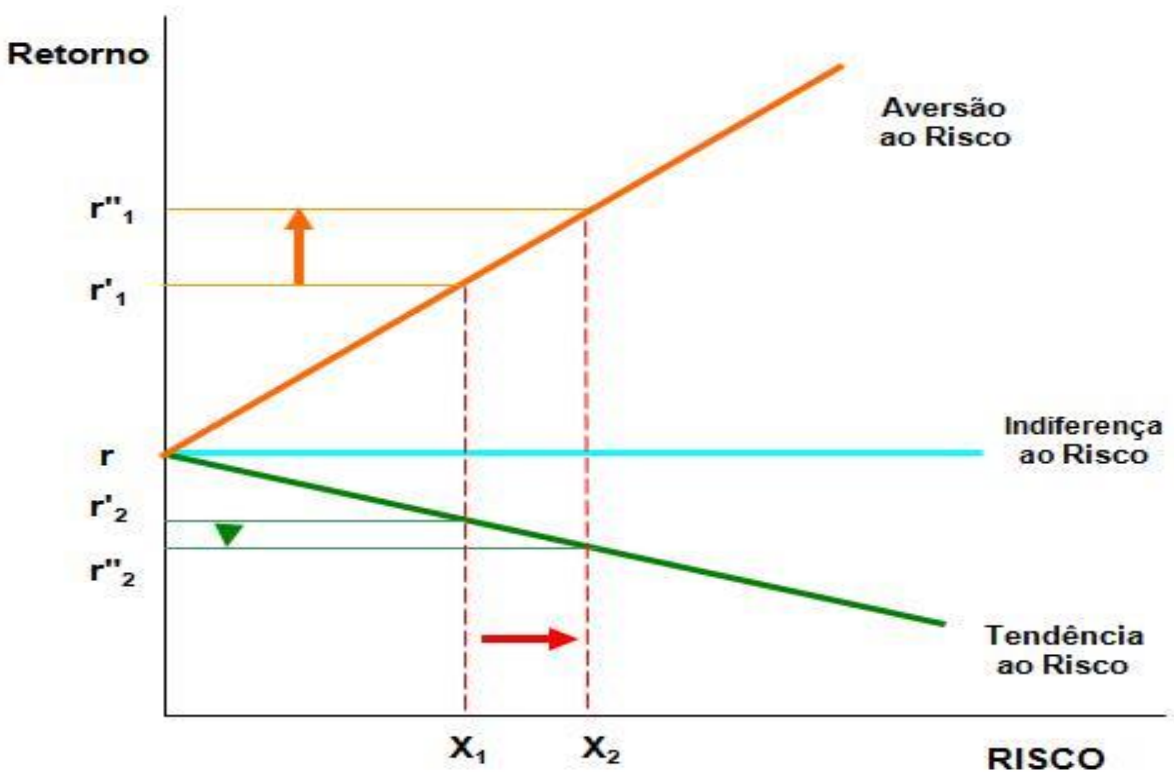

Figura 1: Risco x Retorno

Fonte: Gitman (2001)

Os gestores são, em sua maioria, avessos ao risco, já que, por um dado aumento no risco eles exigem um retorno mais elevado (GITMAN, 2001). Na prática, esses administradores tendem a aceitar apenas aqueles riscos com os quais se sentem seguros. Ao aceitarem riscos, eles, geralmente, tendem a ser agressivos em vez de conservadores.

De acordo com Assaf Neto (2003), não se pode encontrar uma única resposta para todas as situações uma vez que a postura do investidor em relação ao risco é pessoal. Em uma situação de 
incerteza, para se tomar decisões de investimento, a preocupação maior é expressar as preferências do investidor em relação ao conflito risco/retorno.

O investidor típico tem aversão ao risco, embora haja muitos indivíduos com maior tolerância ao risco. O viés da aversão ao risco faz com que os investidores mantenham por muito tempo investimentos que não deram certo, na esperança de recuperarem a perda e diminuir o incômodo do prejuízo. Também faz com que os investidores vendam muito cedo investimentos que geraram lucro, fazendo com que percam o benefício de potenciais lucros desses investimentos. A teoria da preferência tem como objetivo mostrar como um investidor se posiciona diante de investimentos que apresentam diferentes combinações de risco e retorno. No entanto, os indivíduos, geralmente, aplicarão em um ativo com risco somente se seu retorno esperado compensar seu risco (ASSAF NETO, 2003).

Gitman (2001) destaca a importância de se avaliar o risco do ponto de vista comportamental e quantitativo. Para se ter uma noção de risco, pode-se usar a análise de sensibilidade, enquanto que para se fazer uma avaliação mais quantitativa do risco, podem ser usados: o desvio-padrão, o coeficiente de variação, as probabilidades e a distribuição probabilística. Os objetivos do investidor devem ser expressos em termos de metas de riscos e retornos. Porque se as metas forem apenas expressadas em termos de retorno, isso pode levar a práticas de investimentos inadequadas pelo gestor do portfólio, tais como o uso de estratégias de investimento de alto risco ou especulação de carteira. Logo, é imprescindível que seja feita uma análise cuidadosa em relação ao perfil de risco do investidor.

De acordo com a empresa de consultoria financeira Morningstar (2009), a tolerância ao risco não depende apenas da intuição e do perfil psicológico do investidor, mas também de outros fatores como a situação socioeconômica, idade, etc. Pessoas mais jovens podem investir uma parcela maior do seu patrimônio em renda variável porque em situações de perdas financeiras significativas, elas terão tempo suficiente para recuperarem suas posições. Assim, quando estiverem mais velhas, será necessário mudarem gradualmente para posições conservadoras de forma segura, ou seja, diminuir a porção dos investimentos, em renda variável, enquanto aumenta a parcela da renda fixa em sua carteira de investimentos.

Para se construir um portfólio para fundo de pensão, o investidor pode observar a diferença na relação entre risco e retorno quanto ao prazo de investimento e a renda esperada. Levando-se em consideração uma meta de investimento aos 25 anos e supondo que esse investidor possua um emprego estável e uma boa reserva financeira, dependendo das suas preferências por risco, ele pode selecionar uma estratégia de risco moderado e passar depois para porções altas porque a renda corrente obtida pelo seu trabalho provavelmente crescerá ao longo do tempo.

Em se tratando de uma meta de investimento aos 60 anos, supõe-se que o típico investidor de 60 anos também possui uma boa reserva financeira e irá se aposentar em alguns anos, provavelmente, ele irá se expor menos ao risco do que o investidor de 25 anos.

Portanto, um investidor avesso ao risco escolherá uma combinação de renda corrente e estratégia de preservação de capital, já um investidor mais tolerante ao risco escolherá uma combinação de renda corrente e retorno total com a tentativa de ter um crescimento de capital que ultrapasse a inflação (MORNINGSTAR, 2009). Pode-se dizer que há uma extensa literatura a respeito desse tema. Segundo Araújo e Montini (2015), desde o modelo proposto no artigo de Markowitz (1952), esse assunto é amplamente discutido no meio científico. Diante do exposto, 
considera-se relevante o debate sobre quais medidas de risco melhor se ajustam ao perfil do investidor.

\section{METODOLOGIA}

As referências teóricas sobre o tema tem sido largamente corroborativas aos pressupostos teóricos postulados sobre a Moderna Teoria do Portfólio. Ainda assim, não foram exaustivas as iniciativas acadêmicas que explicassem vários comportamentos de carteiras distintas. Quanto aos fins, a pesquisa pode ser considerada como descritivo-exploratória, uma vez que, apesar do esforço dos pressupostos teóricos das Finanças Moderna apresentar uma perspectiva de abordagens corroborativas, ainda há a necessidade de se explorar as aplicações teóricas de forma a descrever e explicar fenômenos que interferem na escolha do perfil do investidor.

Inicialmente, escolheu-se a metodologia de análises de regressão múltipla para identificar correlações entre variáveis explicativas como sexo, idade, tempo de adesão ao plano, grau de escolaridade, formação acadêmica, área de atuação, cargo, tempo de trabalho na COSERN, aquelas que os avaliam em relação ao grau de conhecimento do mercado financeiro e a variável dependente "perfil de investimento".

Assim, desenvolveu-se um instrumento de coleta de dados (formulário) envolvendo perguntas fechadas relativas às variáveis explicativas e foi aplicado de forma aleatória através de correio eletrônico e aplicação presencial do formulário para o universo de 731 participantes ativos da FASERN, durante o período de 16 a 21 de dezembro de 2012. Dois quais retornaram 103, o que corresponde a $14 \%$ dos respondentes desse fundo de pensão. Portanto, pode-se dizer que, segundo Hair (2005), é um número aceitável para representatividade do comportamento do grupo em estudo.

Os dados foram analisados de forma quantitativa, utilizando como ferramentas estatísticas as análises descritivas, de cluster e discriminante. Os resultados obtidos foram tratados através do software SPSS (Statistical Package for the Social Sciences), versão 17.0, e Microsoft Excel, versão 2010. O Excel foi utilizado para a tabulação dos dados e o SPSS foi utilizado para o tratamento estatístico dos dados. Em primeiro lugar, os dados foram analisados através da análise descritiva, que tem como principal objetivo descrever o comportamento da amostra quanto ao desempenho das variáveis, através do uso de medidas de posição, como média, distribuições de frequência e gráficos. Esta análise foi utilizada principalmente para comparação entre os grupos que participaram que tinha como variável independente o perfil de risco escolhido pelo participante da FASERN.

No segundo momento, aplicou-se a Análise de Cluster, também conhecida como análise de conglomerados. Segundo MALHOTRA (2001) define a análise de conglomerados como uma técnica usada para classificar objetos ou casos em grupos relativamente homogêneos chamados conglomerados. De acordo com esse autor, os conglomerados obtidos devem apresentar tanto uma homogeneidade interna (dentro de cada três conglomerados), sendo semelhantes entre si, como grande heterogeneidade externa (entre conglomerados), se diferenciando dos demais. De uma forma geral, as técnicas de agrupamento ou processos de aglomeração se dividem em 3 grupos de análises: as técnicas hierárquicas, as técnicas de partição (não-hierárquicas) e as técnicas de coberturas. Para análise dos dados deste trabalho foram aplicadas as técnicas de Análise 
Hierárquica, sendo utilizada como medida de distância a "distância euclidiana" e como método de aglomeração o método da variância. Então, aplicou-se essas técnicas com o objetivo de formação de grupos ou clusters de acordo com as respostas fornecidas pelos respondentes.

Concluindo esse processo de análise, adotou-se a técnica da Análise Discriminante. De acordo com MALHOTRA (2001), ela "é uma técnica de análise de dados onde a variável dependente é categórica e as variáveis prognosticadoras ou independentes têm natureza intervalar". Para ele, os objetivos da Análise Discriminante se dividem em: estabelecer funções discriminantes, ou combinações lineares das variáveis independentes, que melhor discriminem entre as categorias da variável dependente (grupos); verificar se existem diferenças significantes entre os grupos, em termos das variáveis independentes; determinar as variáveis preditoras que mais contribuem para as diferenças entre grupos; enquadrar, ou classificar, os casos em um dos grupos, com base nos valores das variáveis preditoras; e avaliar a precisão da classificação. Portanto, ao utilizar essas técnicas de análise, objetivou-se definir a que grupo pertence cada participante de acordo com o seu perfil de risco (conservador, moderado e agressivo).

\section{APRESENTAÇÃO E ANÁLISE DE DADOS}

Para a alocação de recursos correspondentes às reservas técnicas, provisões e fundos do Plano CD, a FASERN constituiu cinco perfis de investimentos distintos a partir de fevereiro de 2001, com as regras expressas na norma 003/FASERN/2009, de 15 de dezembro de 2009. Os perfis de investimentos são oferecidos para escolha dos participantes e assistidos, sem restrições, podendo ser alterada a intervalos mínimos de 12 meses, desde a formalização da última opção por um dos perfis de investimentos. A FASERN adota uma política de rebalanceamento na alocação de recursos entre renda fixa e renda variável/investimentos estruturados.

Para a Política de Investimentos de 2013, o rebalanceamento ocorre em duas ocasiões: 1) quando a valorização das carteiras de renda variável/investimentos estruturados ultrapassar $20 \%$ da meta fixada para cada perfil de investimento, ocasião em que os recursos serão realocados da renda variável/investimentos estruturados para a renda fixa; e 2) quando a desvalorização das carteiras de renda variável/investimentos estruturados for maior do que $20 \%$ da meta fixada para cada perfil de investimento, ocasião em que os recursos serão realocados da renda fixa para a renda variável, com o objetivo de atingir a meta definida para cada perfil. Com esse procedimento, a FASERN busca aproveitar a volatilidade do segmento de renda variável, maximizando os retornos das carteiras de seus participantes no longo prazo. Diante dos limitadores e das características inerentes a cada um dos cinco perfis, essa entidade compõe a carteira de investimentos de cada um deles (Tabela 2). Esta informa a meta e os limites inferiores e superiores definidos para cada perfil de investimentos para 2013.

Tabela 2: Limites dos Perfis de Investimentos

\begin{tabular}{|l|c|c|c|}
\multicolumn{1}{c}{$\begin{array}{c}\text { Pe rfil de } \\
\text { Investimento }\end{array}$} & $\begin{array}{c}\text { Renda Variá ve I/Inv. Est ruturados - Limites de Aloca çã o } \\
\text { Inferior (\%) }\end{array}$ & $\begin{array}{c}\text { Meta (\%) } \\
\text { Su perior (\%) }\end{array}$ \\
\hline Conservador & 7,2 & 9,0 & 10,8 \\
\hline Moderado & 11,2 & 14,0 & 16,8 \\
\hline Moderado PI us & 21,6 & 27,0 & 32,4 \\
\hline Agressivo & 28,8 & 36,0 & 43,2 \\
\hline Agressivo plus & 36,0 & 45,0 & 54,0 \\
\hline
\end{tabular}

Fonte: FASERN (Março/2013) 
Então, sabe-se que ao participante é dado o direito de alterar o seu perfil de investimento no intervalo de tempo pré-determinado caso ele considere mais vantajoso. É possível ter acesso, pelo website da FASERN, aos documentos (Estatuto, Código de Ética, Regulamento do Plano, Política de Investimentos, Demonstração Financeira, Normas Internas, Legislação Previdenciária, Guia do Participante, Relatórios, etc.) e consultar dados históricos e acompanhar os resultados da gestão das carteiras de investimentos. Primeiro, distribuiu-se as respostas dos formulários em duas categorias distintas: dados pessoais e conhecimentos do mercado financeiro. De acordo com os resultados obtidos, procurou-se com a aplicação da Análise de Cluster, ou de Conglomerados, dividir a amostra em grupos distintos, utilizando como variáveis as perguntas utilizadas no formulário da pesquisa. A partir dessa análise, aqueles participantes que eram mais homogéneos entre si, foram agrupados dentro da mesma classe, constituídos pelas variáveis escolhidas. Dessa maneira, todas as 103 variáveis foram selecionadas e caracterizadas (Tabela 3).

Tabela 3: Caracterização dos Clusters

\begin{tabular}{|c|c|c|c|}
\hline $\begin{array}{c}\text { Principais perguntas } \\
\text { selecionadas }\end{array}$ & Cluster 1 & Cluster 2 & Cluster 3 \\
\hline Perfil quanto ao risco & Agressivo & Conservador & Moderado \\
\hline Faixa Etária & 51 a 60 anos & 51 a 60 anos & 31 a 50 anos \\
\hline Grau de escolaridade & Graduação & Pós-graduação & Ensino médio \\
\hline Formação acadêmica & Engenharia & $\begin{array}{c}\text { Administração/Economia/Ciências } \\
\text { Contábeis }\end{array}$ & Técnica \\
\hline Área de atuação na empresa & Engenharia & $\begin{array}{l}\text { Financeira e RI e Planejamento e } \\
\text { Controle }\end{array}$ & Operações \\
\hline $\begin{array}{l}\text { Qual seu grau de familiarização com o } \\
\text { mercado financeiro? }\end{array}$ & Intermediário & Intermediário & Baixo \\
\hline $\begin{array}{l}\text { Qual seu nível de conhecimento sobre } \\
\text { o mercado financeiro? }\end{array}$ & Intermediário & Intermediário & Baixo \\
\hline $\begin{array}{l}\text { Como é o seu acompanhamento do } \\
\text { mercado financeiro? }\end{array}$ & Intermediário & Intermediário & Intermediário \\
\hline Qual o seu objetivo de investimento? & Aumento de capital & Geração de renda & Preservação do capital \\
\hline $\begin{array}{l}\text { Qual a sua visão de risco e retorno em } \\
\text { seus investimentos? }\end{array}$ & Moderada & Moderada & Moderada \\
\hline $\begin{array}{l}\text { Qual seria a sua melhor opção de } \\
\text { investimento? }\end{array}$ & $\begin{array}{c}\text { Portfólio E: } 36 \% \text { a } 54 \% \text { (renda } \\
\text { variável) e } 64 \% \text { a } 46 \% \text { (renda fixa) }\end{array}$ & $\begin{array}{c}\text { Portfólio C: } 21,6 \% \text { a } 32,4 \% \text { (renda } \\
\text { variável) e } 78,4 \% \text { a } 67,6 \% \text { (renda fixa) }\end{array}$ & $\begin{array}{c}\text { Portfólio C: } 21,6 \% \text { a } 32,4 \% \text { (renda } \\
\text { variável) e } 78,4 \% \text { a } 67,6 \% \text { (renda fixa) }\end{array}$ \\
\hline Total de Participantes & 68 & 11 & 24 \\
\hline
\end{tabular}

Em conformidade com as análises das características individuais de cada cluster, estabeleceu-se uma nomenclatura particular para cada um deles. O primeiro cluster foi nomeado como Agressivo. Faz parte dele a maioria ou $66 \%$ da amostra total. Nesse grupo observou-se a predominância de participantes com idade entre 51 e 60 anos, com a graduação como nível de escolaridade e com formação em Engenharia e atuação nessa área da empresa. Demonstrou-se ser razoavelmente familiar com o mercado financeiro, possuir um nível intermediário de conhecimento sobre o mercado financeiro e acompanha esse mercado com uma frequência intermediária. Sabe-se que o seu objetivo de investimento é o aumento de capital e a sua visão da relação entre risco e retorno é moderada. No tocante à composição da carteira, o portfólio $\mathrm{E}$ representa a melhor opção de investimento, pois corresponde a proporção da alocação de ativos 
de renda fixa e renda variável do perfil agressivo. Porém, esperava-se que os integrantes desse cluster pertencessem a uma faixa etária mais baixa, formada por pessoas mais jovens, uma vez que esse perfil de investidor está mais disposto a assumir riscos mais elevados na expectativa de obter retornos maiores.

Como Conservador, foi nomeado o segundo cluster. Faz parte dele a minoria ou $11 \%$ de toda amostra. Esse grupo é composto pelos participantes com idade entre 51 e 60 anos, com a pós-graduação como nível de escolaridade e com formação em Administração, Economia e Ciências Contábeis e atuação nas áreas Financeira e Relações com Investidores e de Planejamento e Controle da empresa. Possui um nível intermediário em relação ao seu conhecimento e acompanhamento sobre o mercado financeiro, assim como os participantes com perfil agressivo. Notadamente, o seu objetivo de investimento é a geração de renda e a sua visão de risco e retorno é moderada. Para tanto, esperava-se que a sua preferência fosse a preservação do capital já que esse investidor assume baixos riscos. No entanto, a escolha pelo portfólio C (perfil moderado), como a melhor opção de investimento, não está alinhado com o seu atual perfil conservador.

O terceiro cluster foi denominado de Moderado. Pode-se dizer que 23\% da amostra pertencem a esse conglomerado. Nesse grupo, se destacaram os participantes com idade entre 31 e 50 anos, com o ensino médio como nível de escolaridade, com formação técnica e atuação na área de Operações da empresa. Demonstrou ter pouco conhecimento e um acompanhamento razoável sobre o mercado financeiro. Ele tem como objetivo de investimento a preservação do capital, já a sua visão de risco e retorno é moderada. Logo, optou-se pelo portfólio C, como a melhor opção de investimento, demonstrando ser compatível com o seu atual perfil.

Quanto aos aspectos pessoais dos respondentes, observa-se na amostra a predominância dos participantes do sexo masculino, $78 \%$ do total (Figura 2 ).

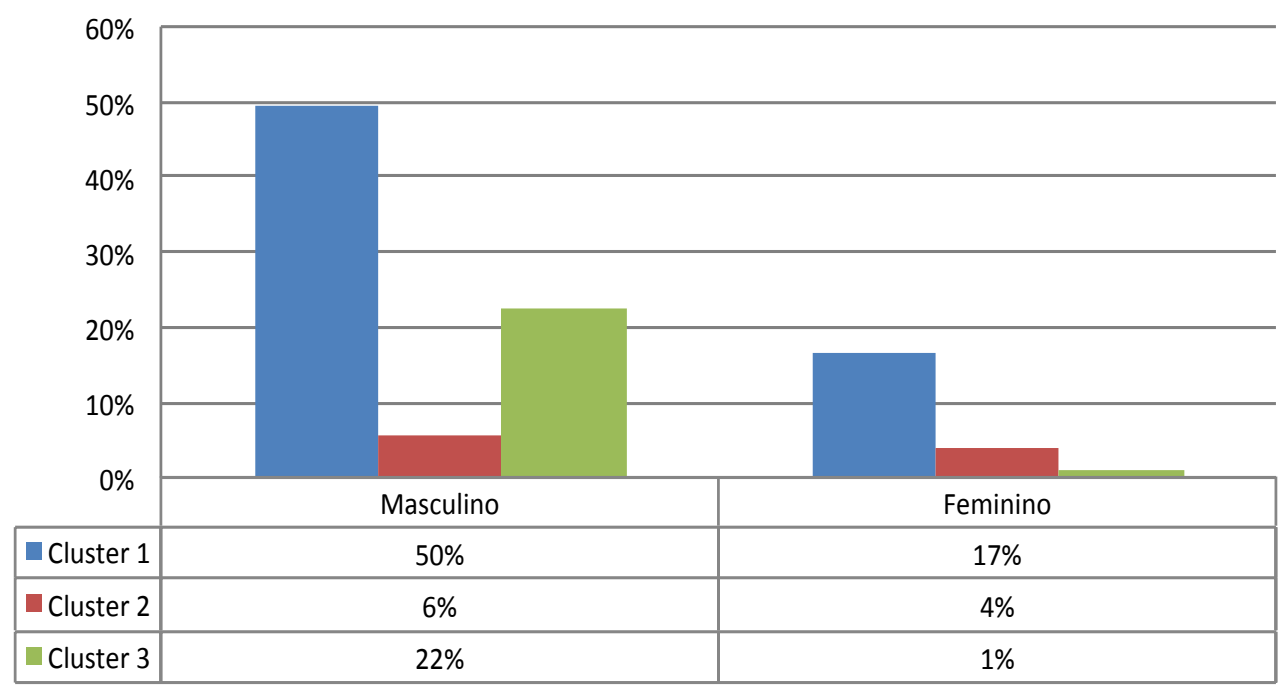

Figura 2: Sexo

Em relação à escolha de um dos 5 (cinco) perfis de investimentos (Figura 3) que o participante deve fazer, é possível saber que $46 \%$ deles estão no agressivo plus e $13 \%$ no agressivo, logo a maioria mostra-se ter uma tolerância maior ao risco. 


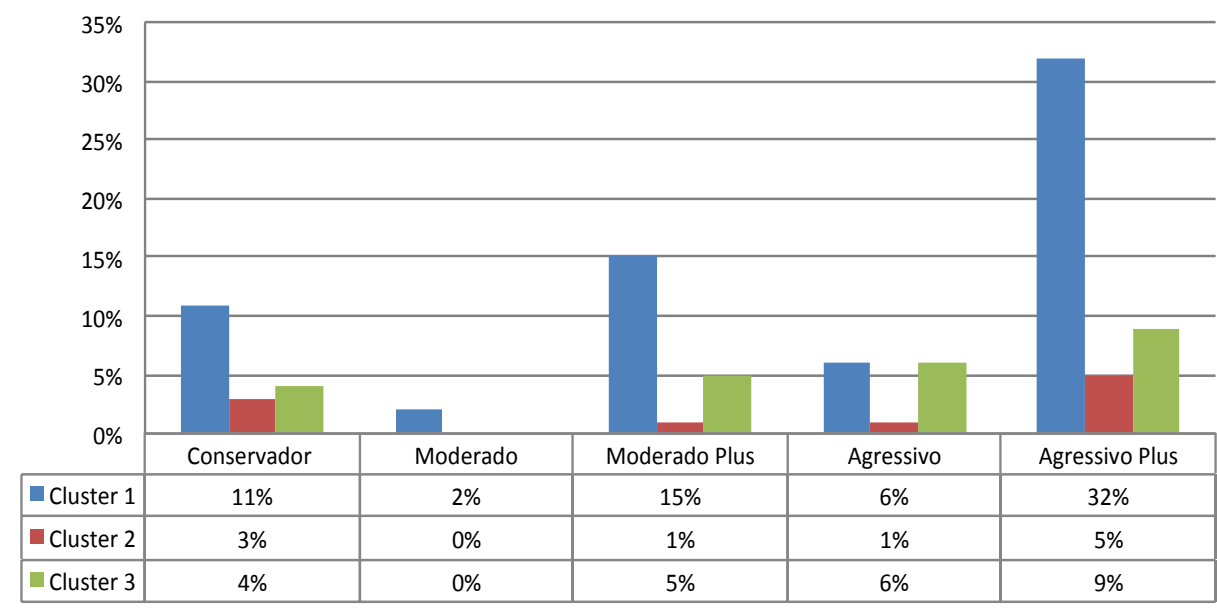

Figura 3: Perfil de risco

A maioria deles tem entre 30 e 50 anos, estão na entidade há mais de 11 anos, tem uma graduação ou pós-graduação completa ou estão cursando uma pós-graduação, tem formação em Administração, Economia ou Ciências Contábeis, está no cargo de analista e atua nas áreas Financeira e de Relações com Investidores, Planejamento e Controle e Operações. Já $21 \%$ dos participantes optaram pelo perfil moderado plus e $2 \%$ pelo perfil moderado, logo pode-se afirmar que eles estão em um nível de risco intermediário. A maioria deles tem mais de 51 anos, estão na entidade há mais de 11 anos, tem um grau de escolaridade similar aos que têm o perfil agressivo, exceto por existir um número maior de pessoas com o ensino médio, tem formação em Engenharia, Direito ou em algum curso técnico, está no cargo de agente e atua nas áreas de Engenharia e Operações.

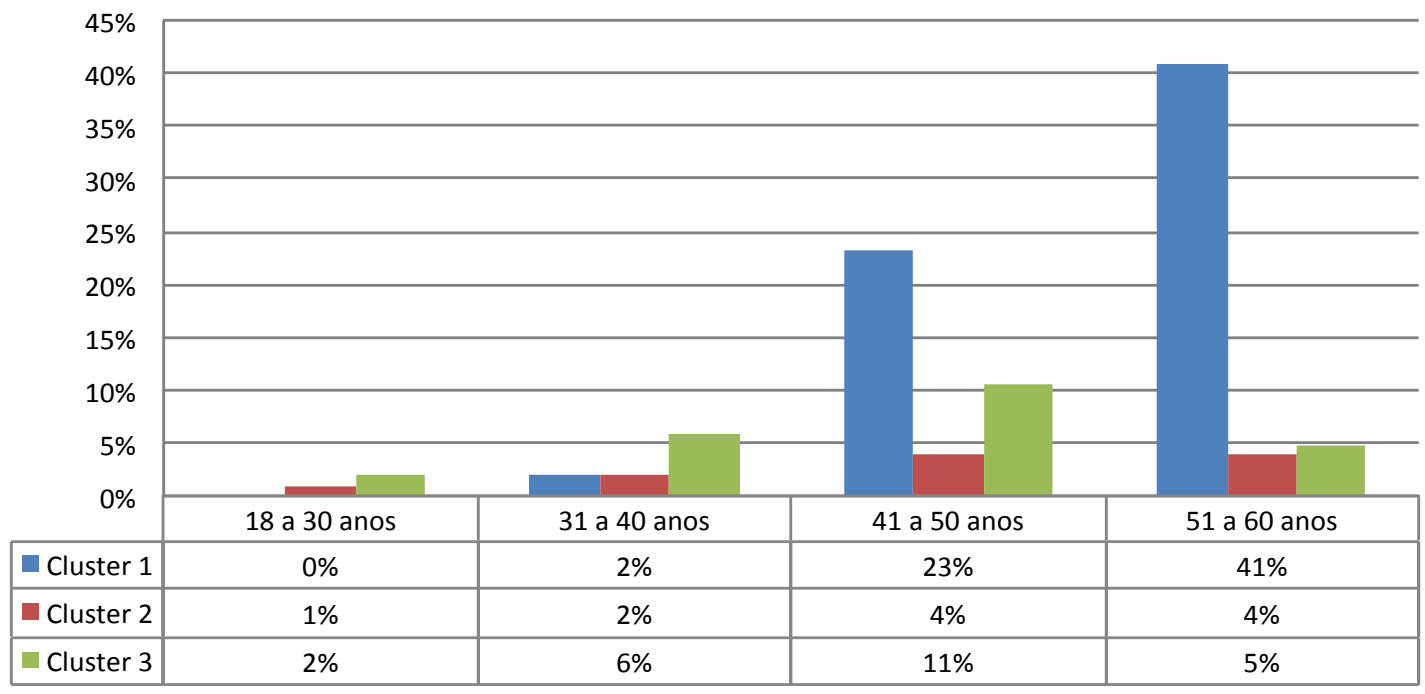

Figura 4: Faixa etária

Fazem parte do perfil conservador $18 \%$ dos participantes, portanto essa parcela se expõe menos ao risco. A maioria deles tem mais de 51 anos, está na entidade há mais de 11 anos, possui o ensino médio completo, tem formação técnica, está no cargo de eletricista ou agente e atua na área de Operações.

De acordo com a faixa etária (Figura 4), 50\% deles têm entre 51 e 60 anos, 38\% entre 41 e 50 anos, $10 \%$ entre 31 e 40 anos e 3\% entre 18 e 30 anos. Logo, há uma expressiva maioria formada por participantes com idade superior a 40 anos, havendo uma concentração maior na faixa acima 
dos 51 anos. Então, espera-se que a maior parte deles seja de perfil conservador já que existe uma relação inversamente proporcional da tolerância ao risco com a idade. Contudo, observa-se que $59 \%$ dos participantes possuem um perfil agressivo.

Considerando o grau de escolaridade (Figura 5), observa-se que $34 \%$ do total possui graduação completa. Já $15 \%$ deles iniciou um curso de graduação, mas ainda não concluiu; $27 \%$ possui ensino médio completo; $17 \%$ pós-graduação completa, todavia $7 \%$ de toda amostra começou um curso de pós-graduação, porém está em andamento; $1 \%$ deles possui mestrado. Também, verifica-se que não havia nenhum cursando ou que havia cursado um Programa de Doutorado ou Pós-Doutorado.

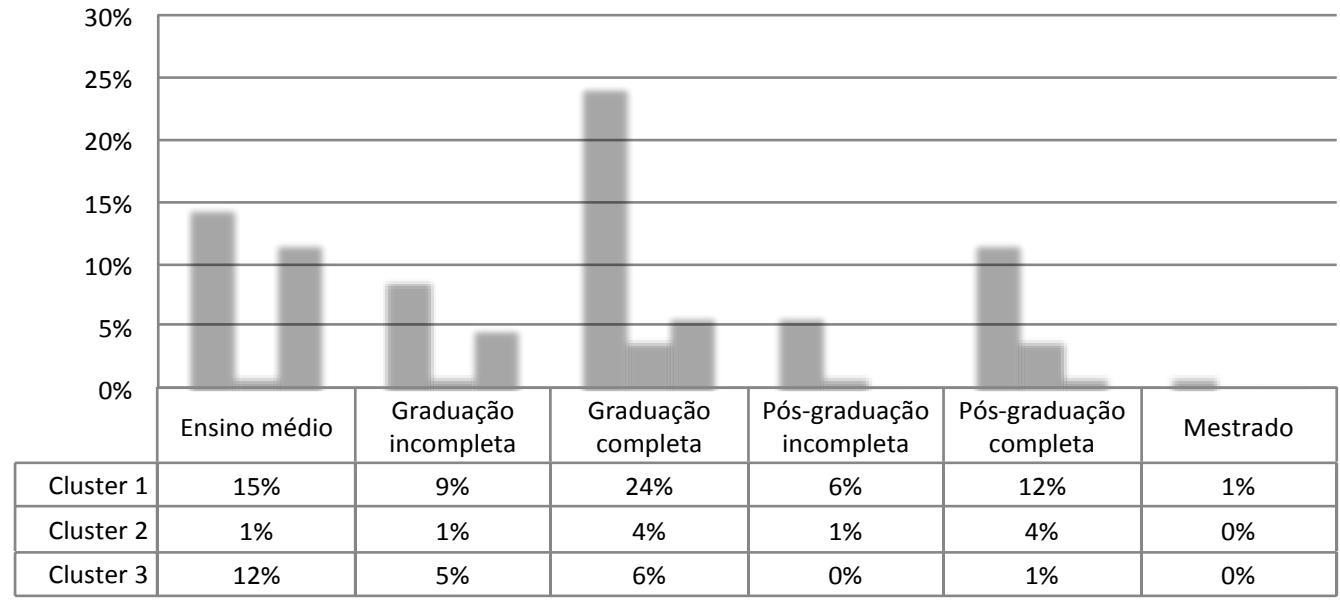

Figura 5: Grau de escolaridade

Um outro fator relevante é a formação acadêmica (Figura 6). Considera-se que $31 \%$ dos participantes têm formação técnica; $14 \%$ possuem formação em Administração; $13 \%$ em Ciências Contábeis; 12\% em Engenharia; 9\% em Economia; 5\% em Direito; 2\% são analistas de sistemas e $17 \%$ têm formação em outras áreas.

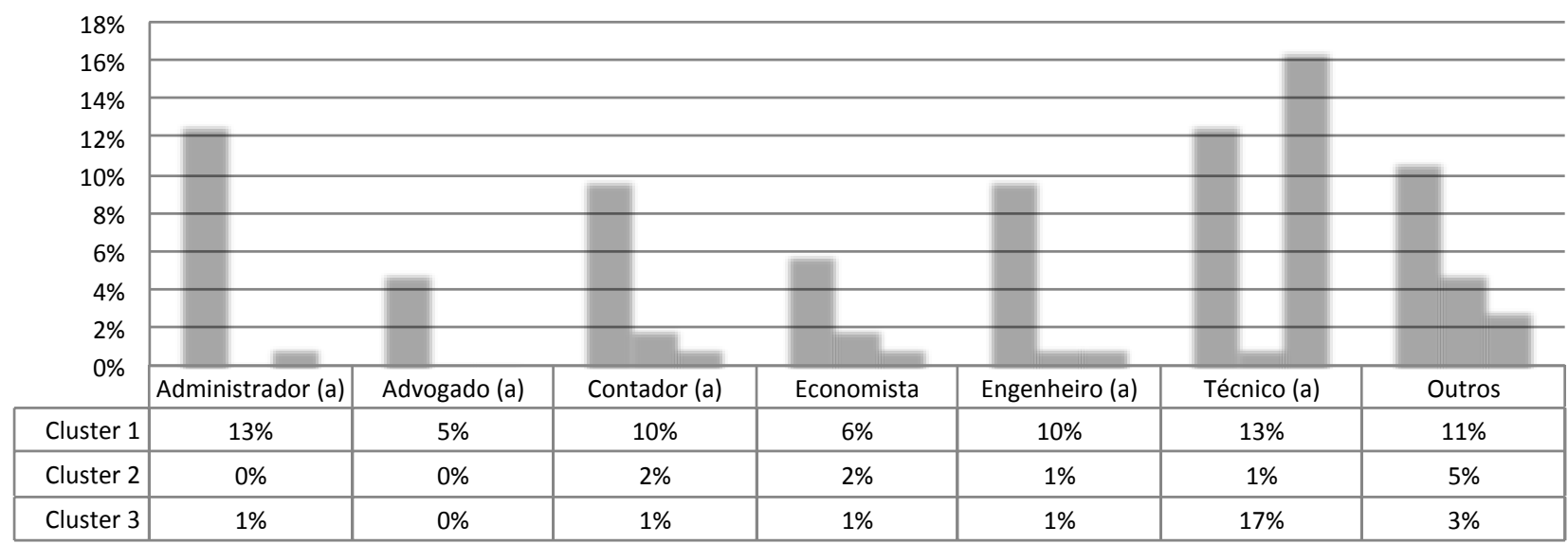

Figura 6: Formação acadêmica

Uma outra variável observada foi a área de atuação do participante na COSERN (Figura 7). Por ela ser uma distribuidora de energia elétrica, espera-se um número maior de funcionários lotados nas áreas de operações - 35\% - e, engenharia - $23 \%$ - o que de fato representa a maioria além de estar em equivalência com o número de formados em cursos técnicos e de engenharia uma vez que é prerrogativa para atuação deles nessas áreas. 


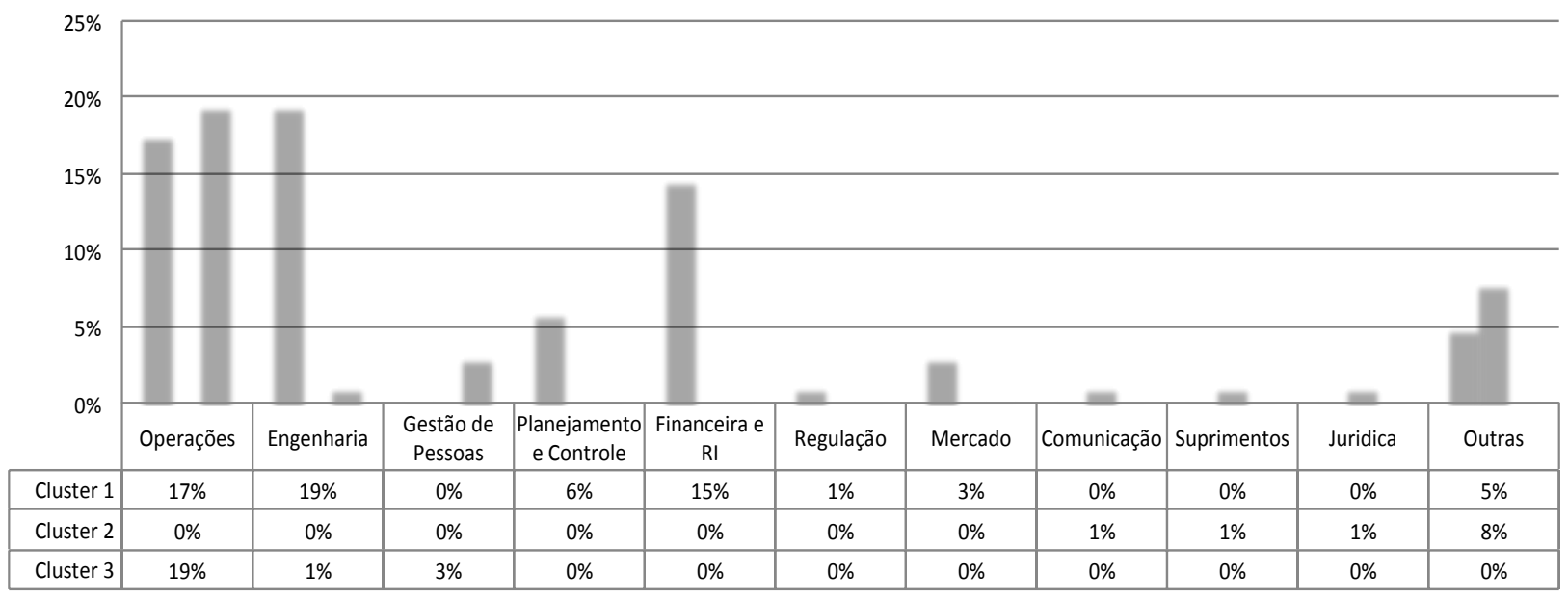

Figura 7: Área de atuação

Um outro dado considerado é o tempo de adesão à FASERN (Figura 8): cerca de $82 \%$ do total está integrado há mais de 11 anos; $6 \%$ entre 9 e 11 anos; $3 \%$ entre 6 e 8 anos; $6 \%$ entre 3 e 5 anos e 3\% faz parte até 2 anos.

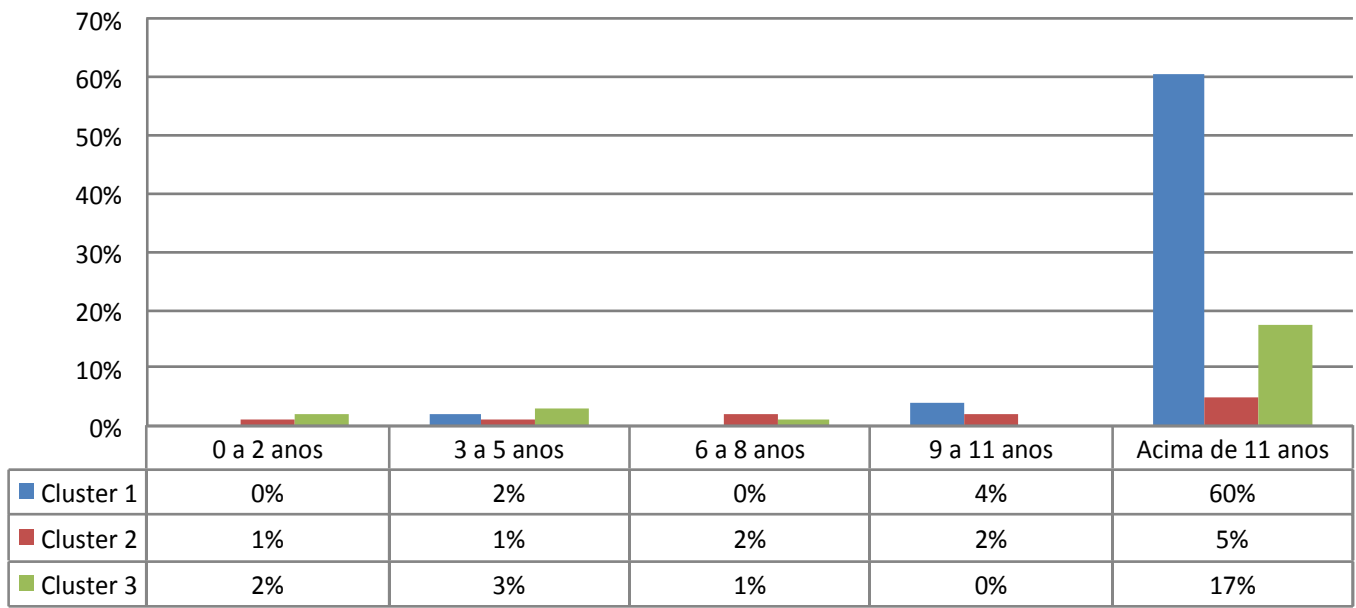

Figura 8: Tempo de adesão à FASERN

Considerando o tempo de trabalho na COSERN (Figura 9), destacam-se aqueles com mais de 20 anos de empresa que correspondem a $86 \%$ do total. Em relação aos demais, $10 \%$ têm até 10 anos na empresa e $4 \%$ têm estado entre 11 e 20 anos.

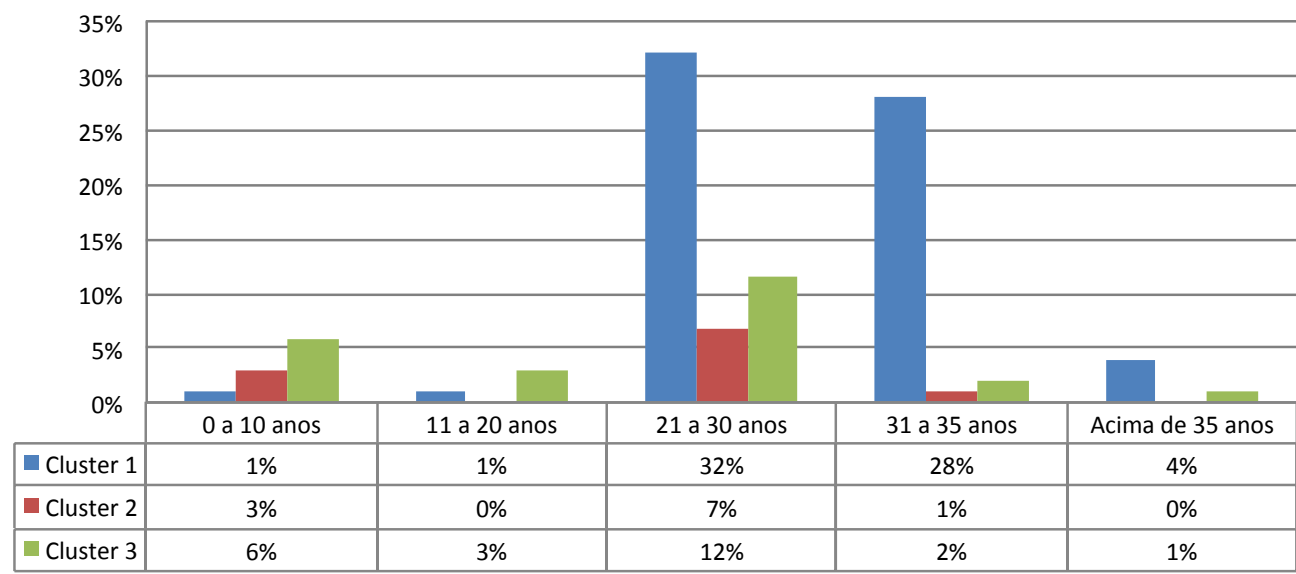

Figura 9: Tempo de trabalho na COSERN 
Quanto ao cargo dos participantes (Figura 10), a amostra apontou um predomínio de 45\% de agentes, seguidos dos $25 \%$ de analistas, $15 \%$ de eletricistas, $8 \%$ de gestores, $4 \%$ de gerentes e $1 \%$ de especialistas, consultores, auditores e superintendentes cada.

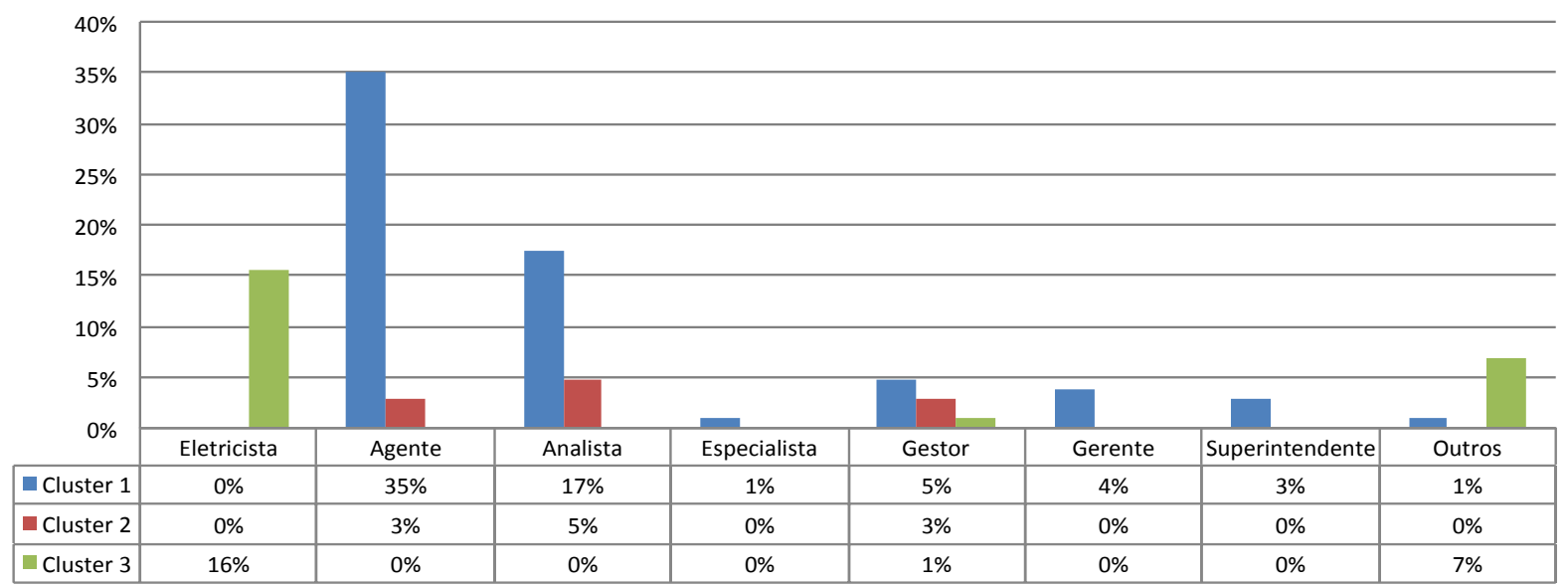

Figura 10: Cargo na COSERN

Quanto a conhecimentos do mercado financeiro tornou possível conhecer que a maioria afirma ter pouco ou razoável grau de familiarização em investimento e seus produtos (Figura 11), portanto o nível de conhecimento observado compreende de baixo a intermediário.

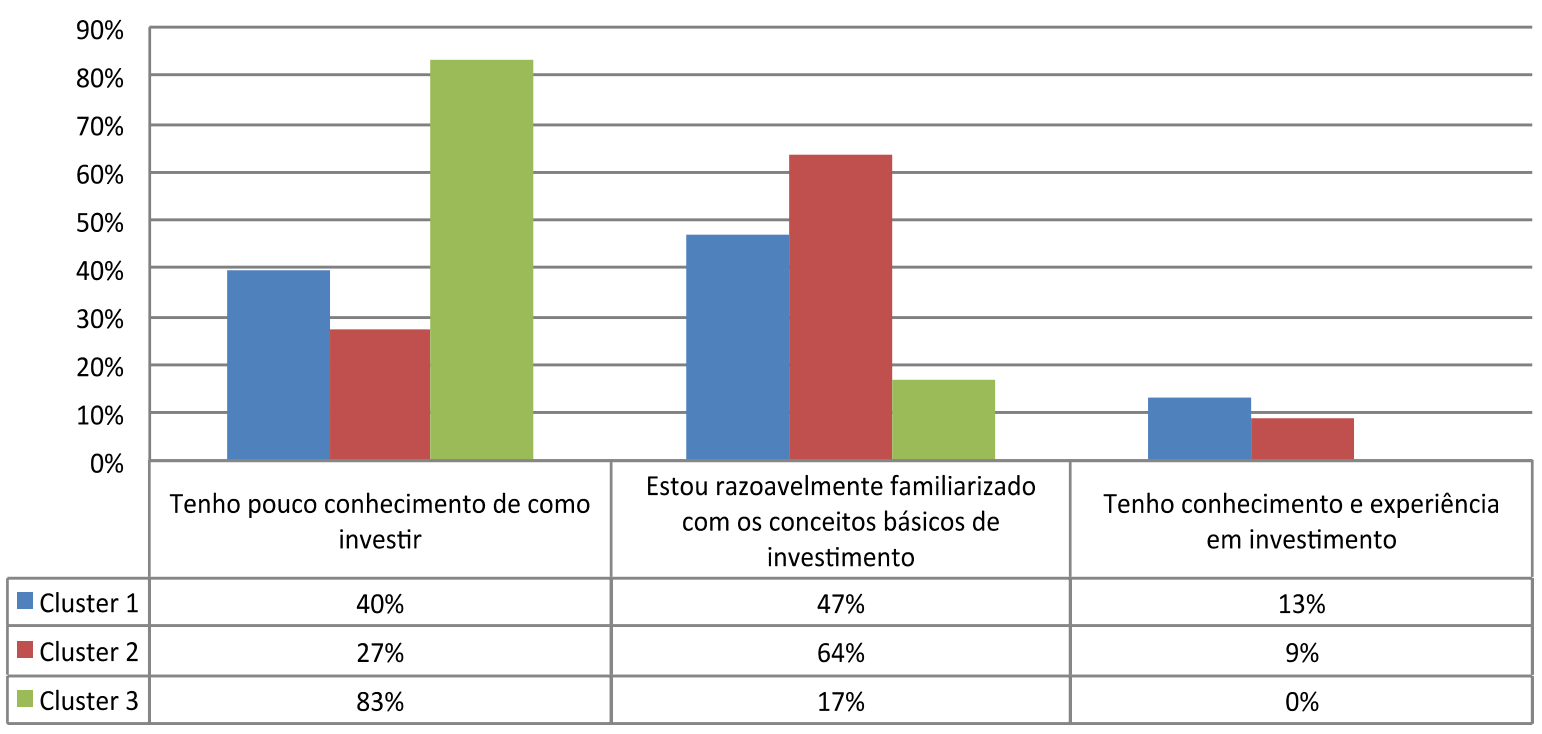

Figura 11: Grau de familiarização com o mercado financeiro

Relaciona-se diretamente o grau de familiarização do investidor com o mercado financeiro com o seu nível de conhecimento (Figura 12). No entanto, apesar de ter observado uma distribuição numérica proporcional entre as perguntas por cluster, esperava-se que houvesse uma repetição relativa na sequência dos clusters por cada pergunta. 


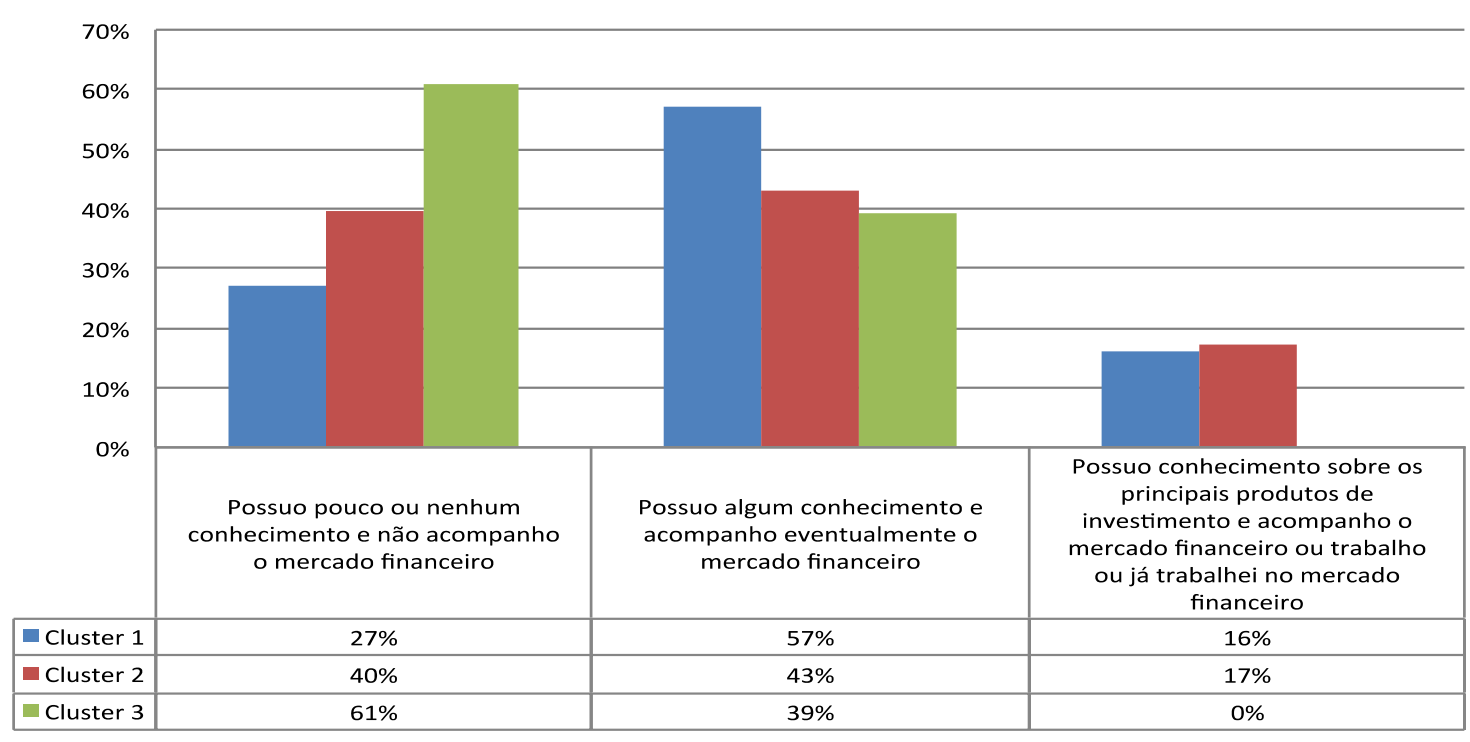

Figura 12: Nível de conhecimento sobre o mercado financeiro

Em relação ao acompanhamento desse mercado (Figura 13), apenas 5\% afirmaram acompanhar por meio de revistas especializadas. Não obstante, $22 \%$ não têm o hábito de ler notícias sobre economia e mercados. Em maior número estão aqueles - 48\%, que acompanham somente as notícias de mercado mais comentadas e de maior destaque e depois estão aqueles $25 \%$, que acompanham por meio de jornais e revistas semanais.

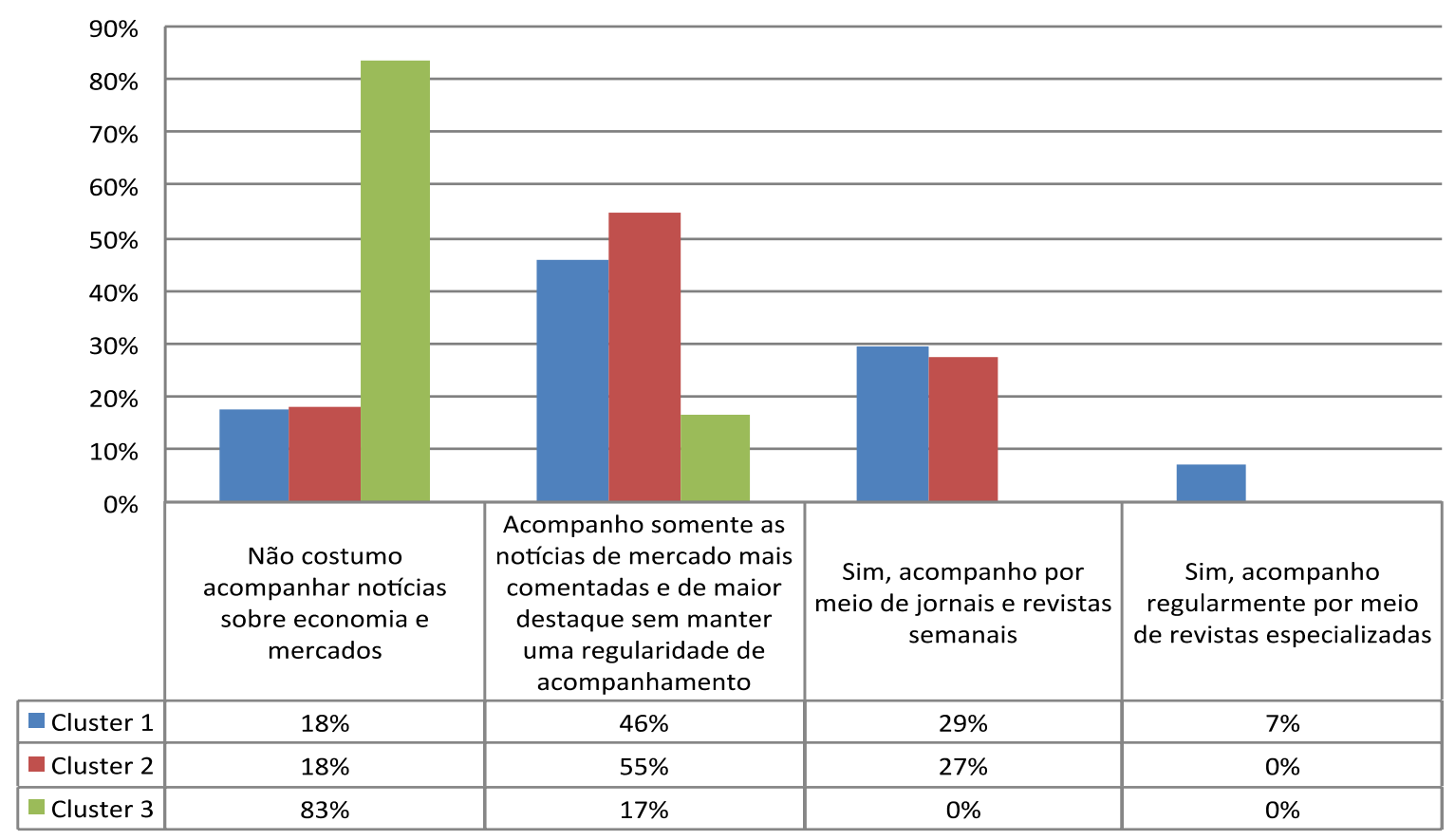

Figura 13: Acompanhamento do mercado financeiro

Quando perguntado qual seria o objetivo de investimento mais adequado ao seu perfil de risco (Figura 14), observa-se que $45 \%$ dos participantes preferem obter um retorno acima da inflação, resultando no aumento do capital investido, o que estaria em consonância com um número maior de optantes pelos perfis agressivo plus e agressivo. 


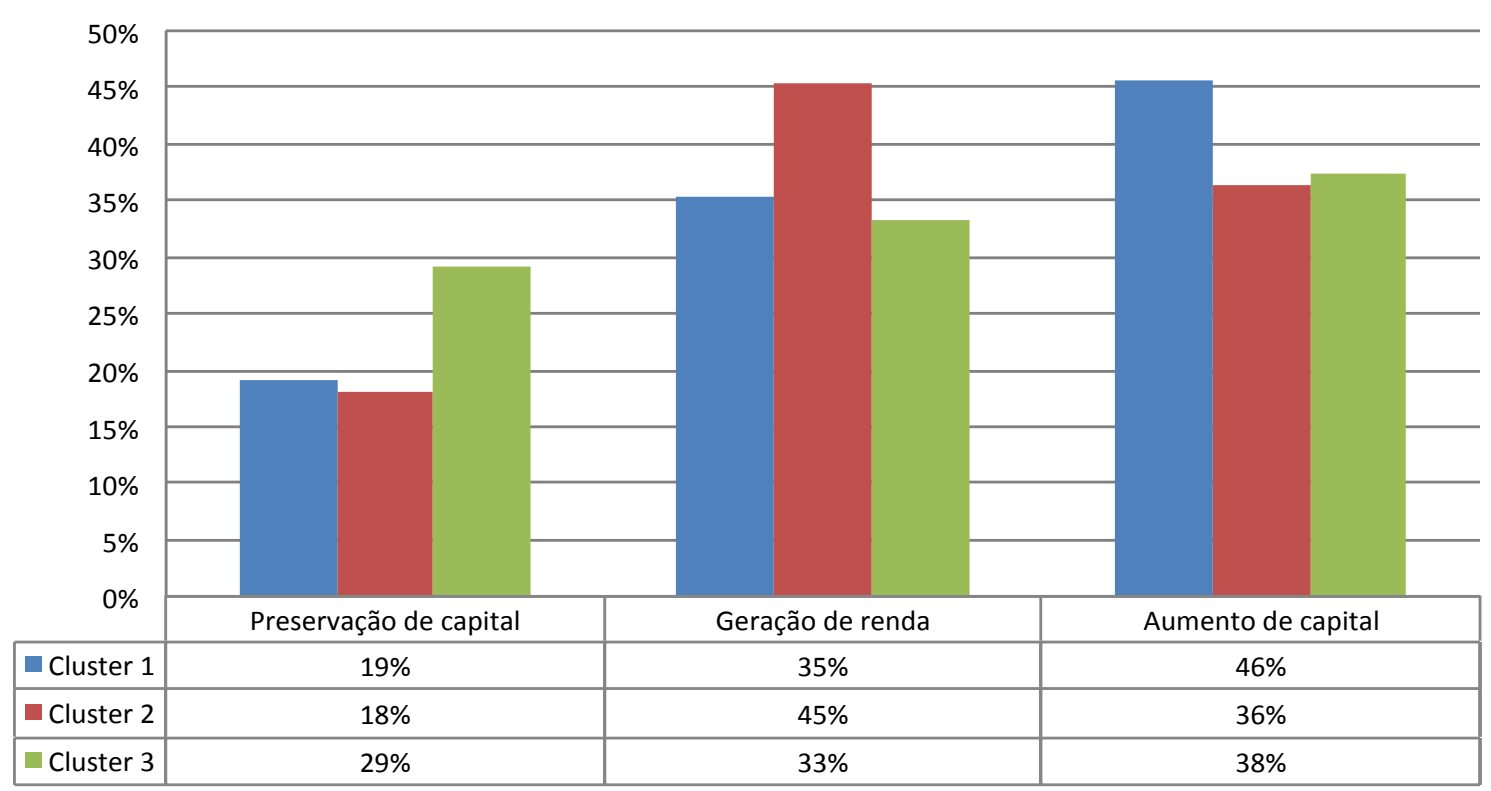

Figura 14: Objetivo de investimento

Para 34\% do total, o objetivo é obter um retorno constante como fonte de renda, gerando um rendimento regular, dos quais $41 \%$ são dos perfis agressivo ou agressivo plus e $59 \%$ pertencem ao perfil moderado. Já $21 \%$ esperam obter um retorno suficiente para compensar a inflação, mantendo o valor real do capital constante. Desse número, $14 \%$ são do perfil moderado ou moderado plus e $86 \%$ pertencem ao perfil conservador.

No entanto, quando a abordagem é a visão de risco e retorno de cada participante (Figura 15), apenas $17 \%$ afirmam aceitar perdas ocasionais em seus investimentos em busca de retornos elevados, $48 \%$ consideram aceitar perdas ocasionais em seus investimentos em busca de retornos maiores desde que elas signifiquem pequenas parcelas do total investido; e $35 \%$ não querem perder capital mesmo que isso signifique que sua rentabilidade seja pequena.

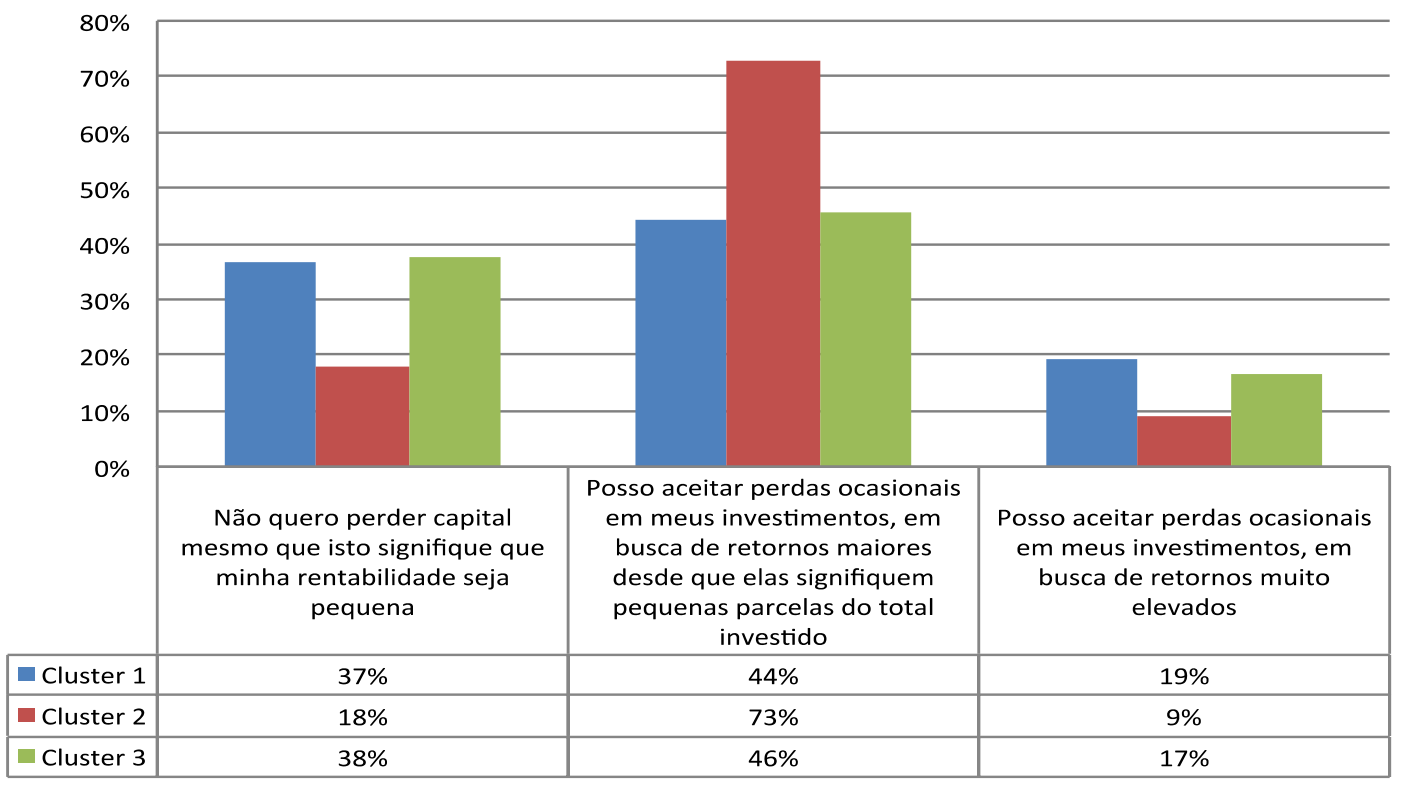

Figura 15: Visão de risco e retorno

Por conseguinte, pode-se dizer que para os que aceitam perdas ocasionais em busca de retornos elevados devem assumir um risco maior na mesma proporção, contudo não se verifica 
uma equivalência em números entre aqueles que optaram pelos perfis agressivo e agressivo plus e os que afirmam ter uma maior tolerância ao risco já que visa retornos maiores.

A fim de que se verificasse o peso de cada variável na formação dos clusters e, definiu-se qual dos três clusters possui o perfil conservador, moderado e agressivo. Depois, realizou-se a análise do Dendrograma pelo qual é possível identificar claramente três conglomerados agrupados de acordo com o seu perfil de risco de investimento. Em seguida, determinou-se a distância entre eles além de atribuir a qual cluster cada um pertence. É possível identificar 3 Clusters no Dendograma (Tabela 4). Aquele denominado de Grupo 1 que varia do 38 ao 43, o outro que corresponde ao Grupo 2 que varia do 28 ao 8 e o Grupo 3 que varia do 76 ao 55.

Tabela 4 - Classificação dos clusters

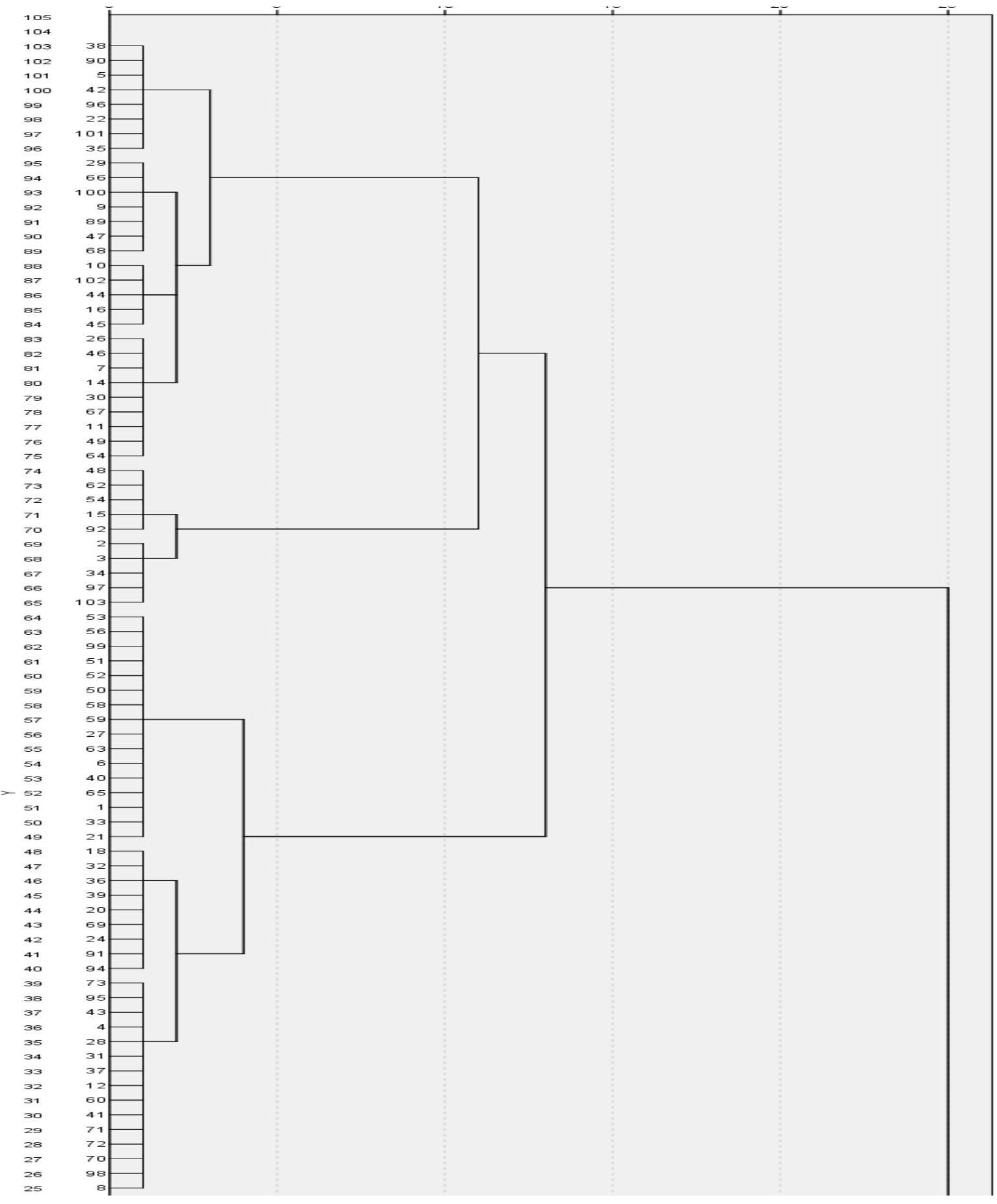




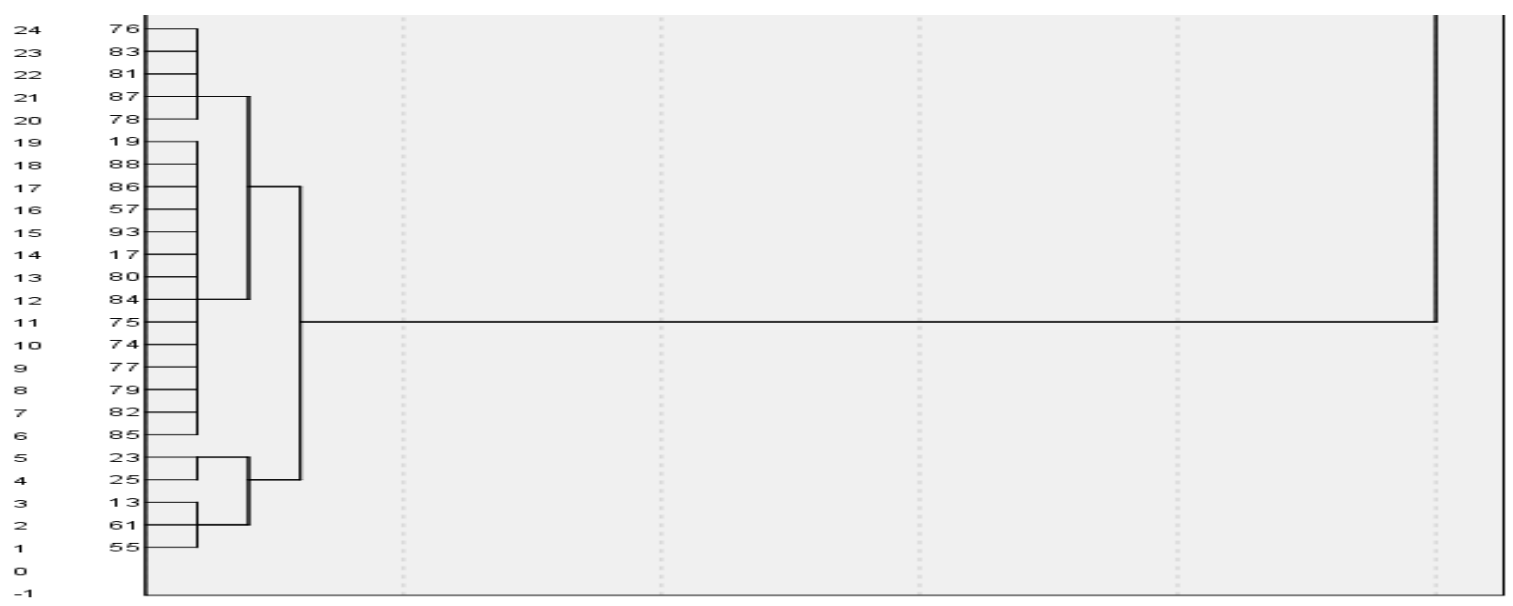

A partir da análise de cluster pelo método não-hierárquico através do método K-means foi possível identificar a significância das variáveis na formação dos clusters, conforme na ANOVA (Análise de Variância) abaixo. Nesse processo, algumas variáveis foram desconsideradas do processo devido à baixa significância (sig > 0,05). Essas variáveis foram retiradas por não apresentarem contribuições significativas para formação dos clusters ou conglomerados. Por outro lado, as variáveis que foram significantes para discriminar os grupos fazem referência à faixa etária, grau de escolaridade, formação acadêmica e área de atuação na empresa. É possível identificar que variáveis foram relevantes para composição dos clusters (Tabela 5). (Regra: todo valor de sig maior que 0,05 significa que a variável não foi significante para formação dos grupos).

Tabela 5 - ANOVA (Análise de Variância)

\begin{tabular}{|c|c|c|c|c|c|c|}
\hline & \multicolumn{2}{|l|}{ Cluster } & \multicolumn{2}{|l|}{ Error } & \multirow{2}{*}{$\mathbf{F}$} & \multirow{2}{*}{ Sig. } \\
\hline & Mean Square & df & Mean Square & Df & & \\
\hline VAR00001 & ,714 & 2 & ,164 & 100 & 4,346 & ,015 \\
\hline VAR00002 & 6,339 & 2 & ,484 & 100 & 13,089 & ,000 \\
\hline VAR00003 & 7,375 & 2 & , 881 & 100 & 8,369 & ,000 \\
\hline VAR00004 & ,381 & 2 & 2,293 & 100 & 166 & ,847 \\
\hline VAR00005 & ,903 & 2 & 155 & 100 & 5,830 & ,004 \\
\hline VAR00006 & ,491 & 2 & ,586 & 100 & ,838 & ,436 \\
\hline VAR00007 & 13,550 & 2 & 1,768 & 100 & 7,663 & ,001 \\
\hline VAR00008 & 38,155 & 2 & 5,870 & 100 & 6,499 & ,002 \\
\hline VAR00009 & 267,255 & 2 & 3,575 & 100 & 74,763 & ,000 \\
\hline VAR00010 & 499,320 & 2 & 1,617 & 100 & 308,703 & ,000 \\
\hline VAR00011 & 9,944 & 2 & 696 & 100 & 14,282 & ,000 \\
\hline VAR00012 & 3,131 & 2 & 382 & 100 & 8,194 & ,001 \\
\hline VAR00013 & 2,433 & 2 & 395 & 100 & 6,154 & ,003 \\
\hline VAR00014 & 1,997 & 2 & 621 & 100 & 3,216 & ,044 \\
\hline VAR00015 & ,217 & 2 & 625 & 100 & 347 & 707 \\
\hline VAR00016 & ,052 & 2 & ,507 & 100 & 103 & ,902 \\
\hline VAR00017 & 2,897 & 2 & 1,968 & 100 & 1,472 & ,234 \\
\hline VAR00018 & 1,681 & 2 & 2,371 & 100 & ,709 & ,495 \\
\hline
\end{tabular}

O teste $\mathrm{F}$ deveria ser usado somente para análises descritivas porque os clusters foram escolhidos para maximizarem as diferenças entre os casos em diferentes clusters. Os níveis de significância observados não são corrigidos para isso e assim não podem ser interpretados como testes de hipóteses que as significâncias dos clusters são iguais. A seguir, realizou-se uma Análise Discriminante (Análise de regressão para quando a variável dependente Y é ordinal). A partir disso, observou-se se as médias entre grupos são diferentes. Assim, a tabela abaixo testa a hipótese nula 
de que as médias dos grupos sejam iguais. Nesse sentido, pela SIG pode-se verificar que a maioria das variáveis são importantes para explicar a formação dos grupos. Pode-se afirmar que isso já era esperado uma vez que foi realizada uma análise similar na análise de Cluster ANOVA. Portanto, a regra é a mesma. Para os valores de sig maiores que 0,05 indicam que a variável em questão não tem poder informativo para discriminar os grupos. Portanto, observa-se que esta análise é mais robusta que a anterior e tem várias diferenças. A ANOVA do Cluster era apenas para gerar os grupos e o seu poder preditivo (Tabela 6).

Tabela 6 - Teste de Igualdade de Grupos

\begin{tabular}{|c|c|c|c|c|c|}
\hline & Wilks' Lambda & F & df1 & df2 & Sig. \\
\hline VAR00007 &, 867 & 7,663 & 2 & 100 &, 001 \\
VAR00008 &, 885 & 6,499 & 2 & 100 &, 002 \\
VAR00009 &, 401 & 74,763 & 2 & 100 &, 000 \\
VAR00010 &, 139 & 308,703 & 2 & 100 &, 000 \\
VAR00011 &, 778 & 14,282 & 2 & 100 &, 000 \\
VAR00012 &, 859 & 8,194 & 2 & 100 &, 001 \\
VAR00013 &, 890 & 6,154 & 2 & 100 &, 003 \\
VAR00014 &, 940 & 3,216 & 2 & 100 &, 044 \\
VAR00015 &, 993 &, 347 & 2 & 100 &, 707 \\
VAR00016 &, 998 &, 103 & 2 & 100 &, 902 \\
VAR00017 &, 971 & 1,472 & 2 & 100 &, 234 \\
VAR00018 &, 986 &, 709 & 2 & 100 &, 495 \\
VAR00001 &, 920 & 4,346 & 2 & 100 &, 015 \\
VAR00002 &, 793 & 13,089 & 2 & 100 &, 000 \\
VAR00003 &, 857 & 8,369 & 2 & 100 &, 000 \\
VAR00004 &, 997 &, 166 & 2 & 100 &, 847 \\
VAR00005 &, 896 & 5,830 & 2 & 100 &, 004 \\
VAR00006 &, 984 &, 838 & 2 & 100 &, 436 \\
\hline
\end{tabular}

Esse pressuposto é verificado através do Teste M. de Box. Testa-se a homogeneidade das matrizes de variância e covariância com base nos valores dos determinantes das respectivas matrizes (Tabela 7).

Tabela 7 - Resultados dos testes

\begin{tabular}{|ll|l|}
\hline Box's M & & 84,798 \\
F & Approx. & 3,763 \\
& df1 & 20 \\
& df2 & 3279,616 \\
& Sig. &, 000 \\
\hline
\end{tabular}

Embora a pressuposição tenha sido violada, pois sig é menor que 0,05 , a análise não é invalidada, apenas os erros padrões sofrerão maiores dispersões. Como não se trata de um modelo no qual se objetiva promover previsões, a violação não trará perda de generalidade (Tabela 8). 
Tabela 8 - Análise de Variância multivariada

\begin{tabular}{|c|c|c|c|c|c|c|c|c|c|}
\hline \multirow{2}{*}{ Step } & \multirow{2}{*}{ Entered } & \multicolumn{9}{|c|}{ Wilks' Lambda } \\
\cline { 7 - 11 } & & Statistic & df1 & df2 & df3 & \multicolumn{4}{|c|}{ Exact F } \\
\cline { 6 - 11 } & & & & & & Statistic & df1 & df2 & Sig. \\
\hline 1 & VAR00010 &, 139 & 1 & 2 & 100,000 & 308,703 & 2 & 100,000 &, 000 \\
2 & VAR00009 &, 059 & 2 & 2 & 100,000 & 154,536 & 4 & 198,000 &, 000 \\
3 & VAR00007 &, 032 & 3 & 2 & 100,000 & 150,062 & 6 & 196,000 &, 000 \\
4 & VAR00002 &, 029 & 4 & 2 & 100,000 & 118,709 & 8 & 194,000 &, 000 \\
\hline
\end{tabular}

a. Maximum number of steps is 36 .

b. Minimum partial $\mathrm{F}$ to enter is 3.84 .

c. Maximum partial $\mathrm{F}$ to remove is 2.71 .

d. F level, tolerance, or VIN insufficient for further computation.

Então, ao final da modelagem é possível identificar que apenas 4 variáveis foram significantes para discriminar os grupos ou explicá-los.

\section{Var10: Área de atuação na empresa \\ Var 9: Formação Acadêmica \\ Var 7: Grau de escolaridade \\ Var 2: Faixa etária}

Abaixo é apresentada a estatística de Wilks que descreve a significância das variáveis no modelo. As quatro são significativas pois sig é menor que 0,05 . Procede-se ao teste de Wilk's Lambda para se determinar o número de funções a serem retidas. Em seguida, apresentam-se os coeficientes da análise das funções discriminantes lineares de Fisher (Tabela 9).

Tabela 9 - Estatística de Wilks

\begin{tabular}{|c|c|c|c|c|c|c|c|c|c|}
\hline \multirow{2}{*}{ Step } & \multirow{2}{*}{$\begin{array}{l}\text { Number of } \\
\text { Variables }\end{array}$} & \multirow{2}{*}{ Lambda } & \multirow{2}{*}{ df1 } & \multirow{2}{*}{ df2 } & \multirow{2}{*}{ df3 } & \multicolumn{4}{|c|}{ Exact $\mathbf{F}$} \\
\hline & & & & & & Statistic & df1 & df2 & Sig. \\
\hline 1 & 1 & ,139 & 1 & 2 & 100 & 308,703 & 2 & 100,000 & ,000 \\
\hline 2 & 2 & ,059 & 2 & 2 & 100 & 154,536 & 4 & 198,000 & ,000 \\
\hline 3 & 3 & ,032 & 3 & 2 & 100 & 150,062 & 6 & 196,000 & ,000 \\
\hline 4 & 4 & ,029 & 4 & 2 & 100 & 118,709 & 8 & 194,000 & ,000 \\
\hline
\end{tabular}

Este procedimento procura identificar, também uma a uma as variáveis estatisticamente mais significantes para compor a função discriminante. $O$ teste de Wilks' Lambda é a estatística padrão usada para denotar a significância estatística do poder discriminatório da função discriminante em questão. $O$ valor do teste pode variar de 0,0 a 1,0 considerando-se que, quanto mais próximo de 1,0, menor será o poder discriminatório da função, sendo o contrário verdadeiro. O modelo tem duas funções discriminantes tendo em vista que se tem três grupos, logo foram elas usadas na análise. É possível ver a significância das funções dos grupos. Elevando-se a correlação canônica ao quadrado se tem o nível de $\mathrm{R}^{2}$ de cada função (Tabela 10).

Tabela 10 - Funções discriminantes

\begin{tabular}{|c|c|c|c|c|}
\hline Function & Eigenvalue & \% of Variance & Cumulative \% & Canonical Correlation \\
\hline 1 & $12,728^{\mathrm{a}}$ & 89,3 & 89,3 &, 963 \\
2 & $1,532^{\mathrm{a}}$ & 10,7 & 100,0 &, 778 \\
\hline
\end{tabular}

Por meio dessa análise, pode-se observar que a primeira função contribui com 89,3\% para o total da variância entre os grupos, sendo efetivamente a que tem o maior poder de separação e a segunda função explica $10,7 \%$ da variância intergrupal. Classificam-se as funções discriminantes 
considerando as quatro variáveis que foram significantes para discriminar os grupos ou explicá-los, além da constante, por cada um dos clusters (Tabela 11).

Tabela 11 - Classificação das funções discriminantes

\begin{tabular}{|c|c|c|c|}
\hline \multirow{2}{*}{} & \multicolumn{3}{|c|}{ Cluster Number of Case } \\
\cline { 2 - 4 } & $\mathbf{1}$ & $\mathbf{2}$ & $\mathbf{3}$ \\
\hline VAR00007 & 2,422 & 2,611 & $-3,004$ \\
VAR00009 &, 652 & 2,785 & 1,732 \\
VAR00010 &,- 458 &,- 290 & 7,698 \\
VAR00002 & 7,112 & 4,961 & 4,587 \\
(Constant) & $-19,4$ & $-29,718$ & $-44,972$ \\
\hline
\end{tabular}

Apresenta-se a distribuição de cada centróide dos grupos e verifica-se a disposição dos grupos em relação a cada função discriminante (Gráfico 2).

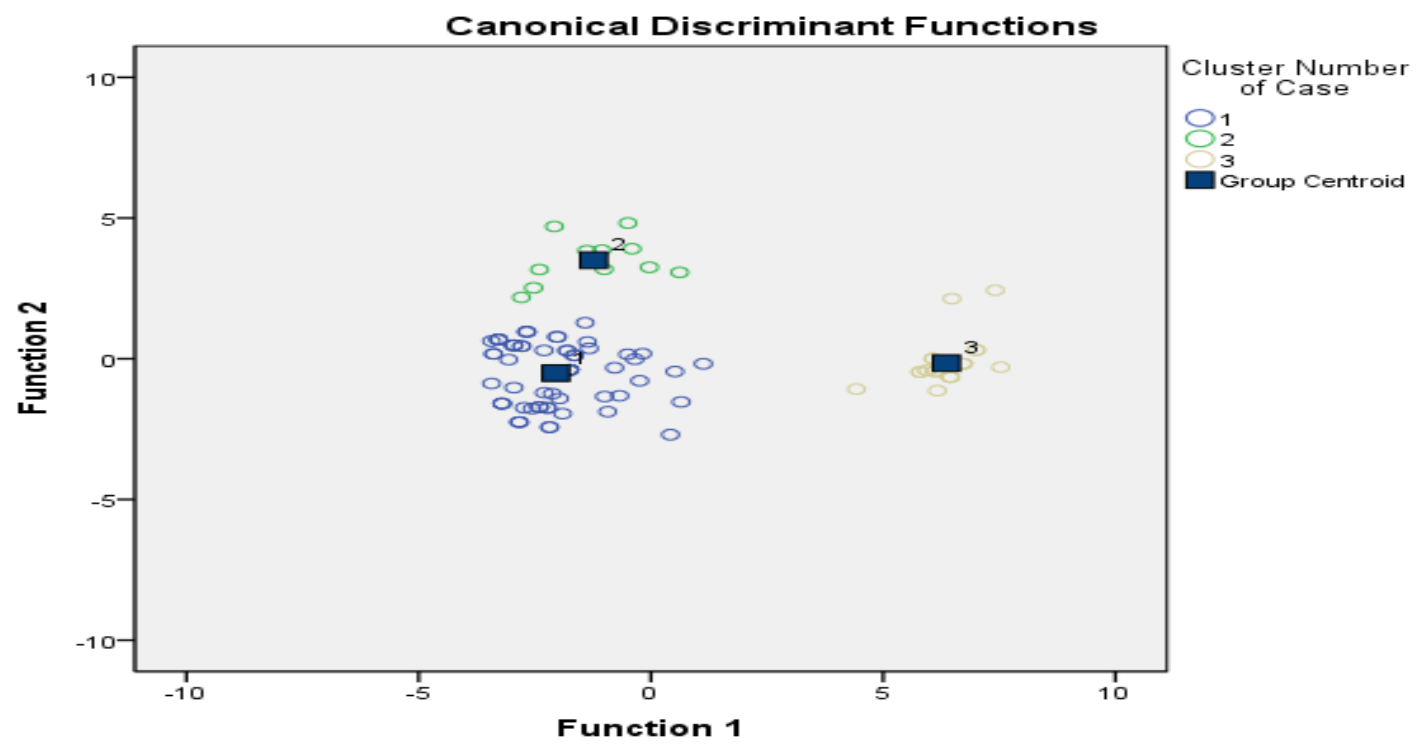

Gráfico 2 - Variações totais das funções F1 e F2

Foram obtidas duas funções discriminantes distintas. As funções F1 e F2 apresentaram capacidade para agrupamentos corretos com valores de $89,3 \%$ e $10,7 \%$ respectivamente. Essas quatro variáveis comprovam que as classificações dos grupos foram realizadas corretamente. Torna-se importante mencionar que se obteve um valor de 0,029 para o lambda de Wilks para a variável 4 que possui o maior poder discriminatório. Logo, torna-se possível afirmar que o resultado desta pesquisa compreende a identificação de três clusters distintos conforme comentários realizados anteriormente. E, acima, percebe-se que o modelo consegue classificar corretamente todos os membros dos clusters.

\section{CONCLUSÃO}

Em cumprimento às políticas de longo prazo para uma carteira de investimento, o participante ativo e o administrador deveriam compartilhar mais informações entre si. Logo, se faz necessário que os usuários entendam a expectativa real para cada tipo de investimento. Além disso, eles precisam entender acerca dos prováveis "eventos desordenados" dentro do longo prazo. Pode-se afirmar que há uma lacuna a ser preenchida com informações sobre os riscos e incertezas, isto é, muitos participantes não se mantém informado sobre o mercado financeiro, 
muito menos acompanha esse universo tão dinâmico. Então, com o compartilhamento de informações necessárias entre os participantes e o administrador, seria possível atender eficazmente a estratégia do investimento.

Apesar de esses administradores saberem mais sobre investimentos e mercado de capital do que um cliente, eles sabem muito pouco sobre as necessidades particulares de cada participante. Isso faz com que esse usuário confie no conhecimento geral do administrador e desempenhe um papel passivo perante as suas possibilidades de atuação na FASERN. Por conseguinte, pode haver um desapontamento entre os participantes em relação aos resultados de longo prazo de suas carteiras de investimento uma vez que eles não estão preparados suficientemente para as responsabilidades de administrar risco, tempo e oportunidade de investimento. Ainda, pode-se dizer que eles têm dificuldade em combinar esses fatores importantes com uma compreensão satisfatória do mercado de capitais dentro de uma estratégia de investimento de longo prazo para uma carteira que terá uma alta probabilidade de atingir seus objetivos para os seus anos de aposentadoria.

Quanto à classificação dos 3 (três) grupos distintos, uma importante constatação realizada baseou-se no fato de que a variável faixa etária não correspondia ao que preconiza a teoria do portfólio. Dessa maneira, existem muitos participantes com idade superior a 50 anos que formam grupos com características associadas ao investidor mais jovem. Isso porque também é permitido permanecer no perfil de risco mais arrojado mesmo quando se atinge uma idade próxima a da sua aposentadoria. As variáveis que correspondem à área de atuação na empresa, formação acadêmica e grau de escolaridade foram importantes para discriminar os grupos, no entanto não foram suficientemente corroborativas para explicar as suas relações com o nível de tolerância ao risco do participante investidor. Logo, pode-se afirmar que esses fatores devem ser levados em consideração para que se deem o suporte apropriado às decisões de investimento.

A discussão acerca deste tema encontra-se muito distante de ser esgotada. Portanto, existe um amplo campo para realização de valiosos estudos teóricos e empíricos que podem ser realizados sobre esta temática. Vale ressaltar ainda que este estudo não só trará à entidade maior compreensão sobre o perfil dos participantes, mas, ao mesmo tempo, trará mais clareza acerca do grau de conhecimento do investidor, o que possibilitará a ambos uma melhor eficiência em processos internos de tomada de decisão. Além disso, propõe orientar os futuros participantes por meio de uma análise de seus perfis para que esses possam tomar a decisão mais adequada às suas características como investidor.

\section{REFERÊNCIAS}

1. ABRAPP. Associação Brasileira das Entidades Fechadas de Previdência Privada. Disponível em: <http://www.abrapp.org.br>. Acesso em: 01 dez. 2013.

2. ARAÚJO, Alcides Carlos de; MONTINI, Alessandra de Ávila. Analysis of risk metrics in share portfolio optimization. Revista de Administração (São Paulo), 2015, 50.2: 208-228.

3. ASSAF NETO, Alexandre. Finanças corporativas e valor. São Paulo: Atlas, 2003.

4. BRIGHAM, Eugene F.; GAPENSKI, Louis C.; EHRHARDT, Michael C. Administração Financeira: teoria e prática. São Paulo: Atlas, 2001.

5. CONSELHO MONETÁRIO NACIONAL. Resolução n. 3.846, de 25 de março de 2010. Sessão 
realizada em 25 de março de 2010, tendo em vista o disposto no art. 9o, § 10, da Lei Complementar no 109, de 29 de maio de 2001.

6. FUNDAÇÃO COSERN PREVIDÊNCIA COMPLEMENTAR. Regulamento do Plano Misto de Benefícios Previdenciários № 001, aprovado pela Portaria № 3.052, com vigência a partir de 29/10/2009. Art. 9o, do capítulo III, do Regulamento do Plano CD (Contribuição Definida).

7. GITMAN, Lawrence Jeffrey. Princípios de Administração Financeira. São Paulo: Pearson Addison Wesley, 2001.

8. HAIR, JR. J. F. et al. Análise multivariada de dados. Porto Alegre: Bookman, 2005

9. MALHOTRA, N.K. Pesquisa de Marketing. Uma orientação aplicada. Trad. Nivaldo M. Jr. e Alfredo A. de Farias. 3. ed. - Porto Alegre: Bookman, 2001.

10. MARKOWITZ, Harry M. Portfolio selection: efficient diversification of investments. John Wiley \& Sons, Inc., New York Chapman \& Hall, Limited, London, 1959.

11. MORNINGSTAR. Metas de investimento conforme faixa etária. Disponível em: <http://www.morningstar.com>. Acesso em: 03 out. 2012.

12. ROSS, Stephen; WESTERFIELD, Randolph W.; JAFFE, Jeffrey F. Administração Financeira. 2. ed. São Paulo: Atlas, 2002.

13. SPC. Secretaria de Previdência Complementar. Disponível em: <http://www.previdencia.gov. br/spc.php>. Acesso em: 16 out. 2012.

14. SPSS 17.0 for Windows [computer program]. Statistical Package for Social Science (SPSS).

15. Versão 17.0.1. Chicago (IL): SPSS Incorporation; 2008. Disponível em: < http://www.spss.com >. Acesso em: 16 out. 2012. 